\title{
Layers, levels and contexts in Functional Discourse Grammar
}

\author{
Jan Rijkhoff
}

\section{Introduction ${ }^{1}$}

This contribution has three main goals. Firstly, so as to be able to accommodate classifying modifiers, I will propose a revised model of the noun phrase, which consists of five concentric layers of modification rather than four, as it did in the previous model (section 2$)^{2}$ It will also be claimed that discourse-referential modifiers, which are specified at the Interpersonal Level, only relate to the status of the referent in the world of discourse (Rijkhoff fc. a; Rijkhoff and Seibt 2005). That is to say, attitudinal modifiers of the kind proposed in Hengeveld (2004b) (see also Hengeveld this volume; Butler this volume) are not deemed to have their own slot in the layered model of the noun phrase defended here.

Secondly, I will propose some modifications regarding the contextual component with special attention to noun phrases and argue that external reality (the "context of situation") needs to be represented by a separate component and that each component of the FDG model constitutes a different kind of context (section 3). A single rule will be proposed to capture the influence of any contextual factor on the form, function or meaning of a linguistic expression.

Section 4, finally, argues that in the current FDG model the Interpersonal Level in the grammatical component contains elements that actually belong to the external component (or "E-context") and proposes alternative schemas for the NP and the clause without variables for Speaker and Addressee. In this proposal the descriptive modifiers (i.e. classifying, qualifying, quantifying, and localizing modifiers) are specified at the Representational Level ("language as carrier of content"). The Interpersonal Level is regarded as that part of the grammatical component that is concerned with "language as exchange" and accommodates three layers of modification, one for things or events, one for propositions, and one for clauses. 


\section{The structure of the noun phrase}

In Rijkhoff (2002) the noun phrase (NP) is analysed as having four layers of modification, accommodating (i) qualifying, (ii) quantifying, (iii) localizing, and (iv) discourse modifiers (or discourse-referential modifiers). It appears, however, that a complete analysis of the NP requires an additional, fifth layer of modification for what might be called classifying modifiers of the noun (as announced in Rijkhoff 2004, fc. a). Moreover, it will be argued that discourse-referential modifiers, which are specified at the Interpersonal Level in the grammatical component, are only concerned with the status of the referent (thing, event) as a discourse entity and not, as Hengeveld (2004a, 2004b, this volume) has claimed, also with emotional or attitudinal phenomena.

This section is structured as follows. After a brief presentation of the "old" four-layered model of the noun phrase (section 2.1), I will argue for the existence of an additional, fifth category of so-called classifying modifiers, which (further) specify what kind of entity is being referred to by the speaker (sections 2.2 and 2.3).

\subsection{The four-layered analysis of the NP}

In Rijkhoff (2002) modifiers in the NP are divided into two main categories: descriptive and discourse-referential modifiers (or representational and interpersonal modifiers respectively). This division reflects the double function of NPs: they provide a physical description of an entity and at the same time they are the constructions used to refer to entities in the world of discourse. Descriptive modifiers specify properties of the referent of the NP or clause in terms of the notions Quality (how it is), Quantity (how much/many it is) and Location (where it is). The fourth and outermost layer of modification accommodates discourse-referential modifiers, which pertain to "THAT IT IS", i.e. they are concerned with the status of things (or events) in the shared world of discourse (e.g. " \pm Definite" for things). Adnominal adjectives, possessives and relative clauses are instances of lexical NP modifiers or "satellites" (symbolized by $\tau$ in Figure 1), because they involve members of lexical categories (verbs, nouns, adjectives, adverbs). Operator slots (symbolized by $\omega$ in Figure 1) are reserved for grammatical modifier categories in the NP such as articles or demonstratives, which can be expressed as free forms, particles or affixes (for a discussion of nominal aspect, see Rijkhoff 2002: 100-121). Figure 1 also shows that clauses can 
be analysed in a similar fashion ( $\pi$ symbolizes operators, $\sigma$ stands for satellites; see Rijkhoff 2002: chapter 7); discourse-referential modifiers, which are symbolized by the variables $\Omega-\Pi-\Sigma-\mathrm{T}$, are discussed further below (Figure 3).

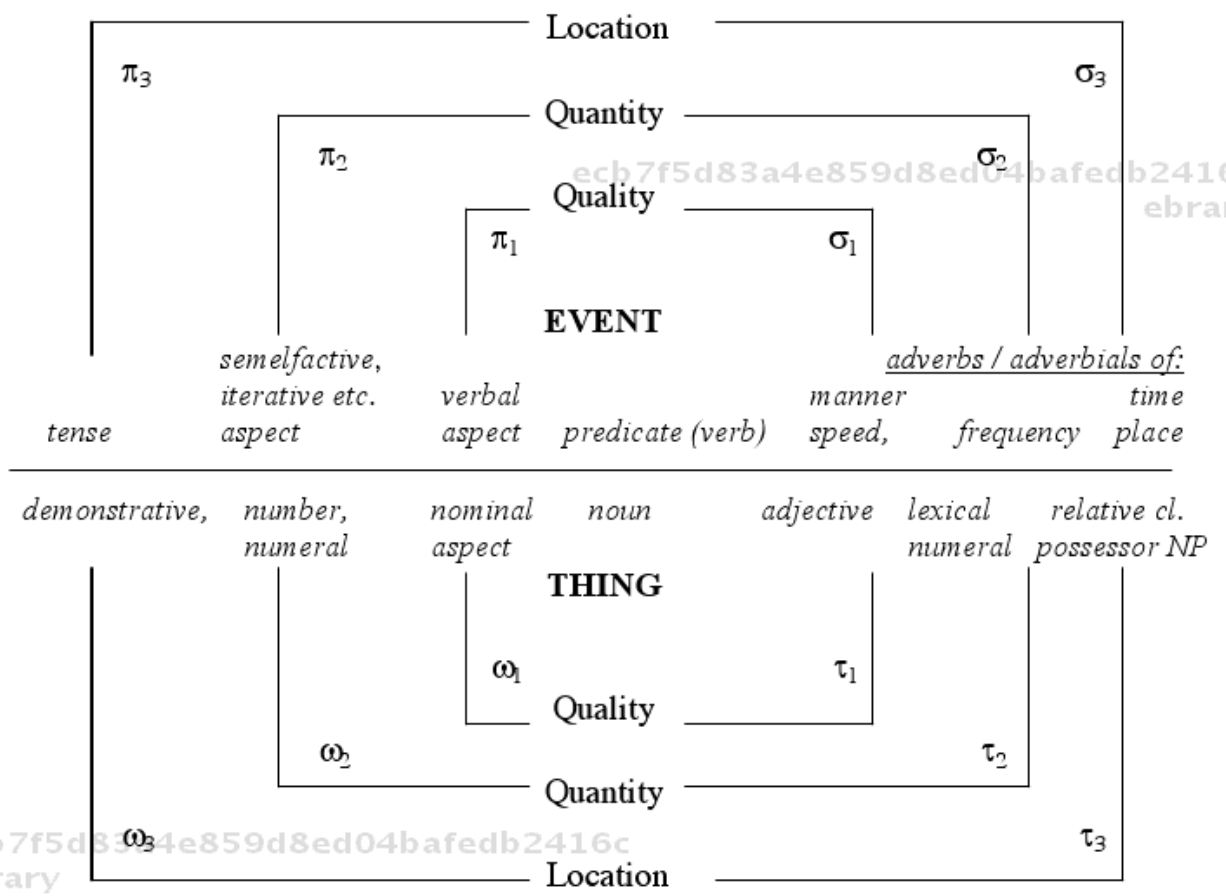

Grammatical expression of Quality, Quantity and Location in the NP

Figure 1. Symmetry in the underlying structure of the clause and the NP as in Rijkhoff 2002: descriptive modifiers (but cf. Figure 10 below).

Languages use only a subset of the modifier categories mentioned in Figure 1 and there is no one-to-one relationship between the form and the function of a modifier (only some typical forms or constructions are specified in Figure 1). For example, in many languages the adnominal distal demonstrative (a localizing operator) is also used as a discourse-referential 
operator to mark definiteness, and relative clauses can be employed as qualifying, quantifying or localizing satellites (Rijkhoff 2002 and fc. a).

A simplified version of the layered NP model is represented in (1), in which each operator $(\omega, \Omega)$ or satellite $(\tau, \mathrm{T})$ takes a certain layer $(\mathrm{L})$ as its argument (cf. Escribano this volume). Note that I am here only concerned with the analysis of NPs used for first-order or spatial entities (symbolized by the $\mathrm{x}$-variable) and that the schema in (1) does not contain the predicate variable $f$ (see Figure 3 and further below on discourse-referential modifiers $\Omega$ and T; (45) in section 2.2 .3 gives the new schema): ${ }^{3}$

$$
\mathrm{NP}_{\mathrm{i}}: \Omega_{4}\left[\omega_{3}\left[\omega_{2}\left[\omega_{1}\left[\operatorname{NOUN}\left(\mathrm{x}_{\mathrm{i}}\right)\right]_{\mathrm{LO}} \tau_{1}\left(\mathrm{~L}_{0}\right)\right]_{\mathrm{Ll}} \tau_{2}\left(\mathrm{~L}_{1}\right)\right]_{\mathrm{L} 2} \tau_{3}\left(\mathrm{~L}_{2}\right)\right]_{\mathrm{L} 3} \mathrm{~T}_{4}\left(\mathrm{~L}_{3}\right)
$$

$\mathrm{x} \quad$ referent variable (symbolizes the referent of the NP);

$\Omega / \omega$ term (NP) operator: $\omega_{1}=$ qualifying operator, $\omega_{2}=$ quantifying operator, $\omega_{3}=$ localizing operator, $\Omega_{4}=$ discourse-referential operator;

$\tau / \mathrm{T}$ term (NP) satellite: $\tau_{1}=$ qualifying satellite, $\tau_{2}=$ quantifying satellite, $\tau_{3}=$ localizing satellite, $\mathrm{T}_{4}=$ discourse-referential satellite.

$\mathrm{L}_{1}$ constitutes the quality layer, which contains the head of the construction and accommodates qualifying operators ( $\omega_{1}$ in the $\mathrm{NP}, \pi_{1}$ in the clause) and satellites $\left(\tau_{1}\right.$ in the NP, $\sigma_{1}$ in the clause). In the 2002 model these modifiers only relate to the property that is designated by the head, such as nominal or verbal aspect markers, (typically) adjectives - if the language under analysis has them - and adverb(ial)s of manner or speed (but cf. section 2.2). The quantity layer $\left(\mathrm{L}_{2}\right)$ contains the quality layer and accommodates quantifying modifiers $\left(\omega_{2}, \tau_{2} ; \pi_{2}, \sigma_{2}\right)$, which have to do with number distinctions (singular, plural) or cardinality. The location layer $\left(\mathrm{L}_{3}\right)$ contains both the quality layer and the quantity layer and accommodates localizing modifiers $\left(\omega_{3}, \tau_{3} ; \pi_{3}, \sigma_{3}\right)$, which specify properties concerning the location of the thing or event, such as demonstratives, tense markers, (localizing) relative clauses or adverb(ial)s such as "in the garden" or "yesterday" (recall there is no direct correlation between form and function of modifiers, especially in the case of satellites). 


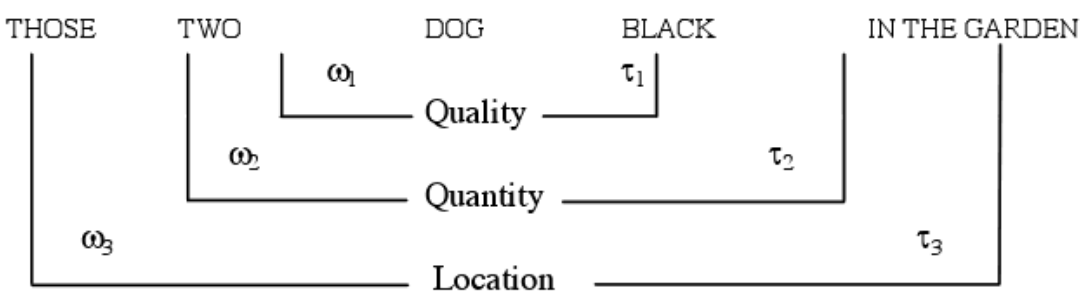

Qualifying, Quantifying and

Localizing operator's in the NP
Qualifying, Quantifying and

Localizing satellites in the NP

Figure 2. Simplified representation of "those two black dogs in the garden".

Thus, in an NP like "those two black dogs in the garden" black only modifies the head noun and the quantifying modifier two specifies the number of black dog entities. Both those and in the garden specify the location of dog entities with all their qualitative and quantitative properties.

In addition to the three descriptive layers shown in Figure 1, the underlying NP/clause structure contains a layer to accommodate modifiers that are concerned with the status of the thing or event as a discourse entity (Figure 3). Here we find values for operators such as Definite or Specific (in the clause: Realis or Actual) and satellites such as "same", "other" (in the clause e.g. "really", "actually"). ${ }^{4}$ Discourse-referential (DR) modifiers appear in the outermost layer, as they have the descriptive modifiers in their scope (see also Figures 14 and 15 on other interpersonal modifier categories).

Parallels between discourse-referential operators in the clause and in the NP are particularly interesting because of the various relationships that hold between realis/irrealis and definiteness/indefiniteness. I will show below that, in order to understand these relationships, we must make crucial reference to the grammatical category of specificity (see Rijkhoff and Seibt 2005 for a more detailed discussion). 


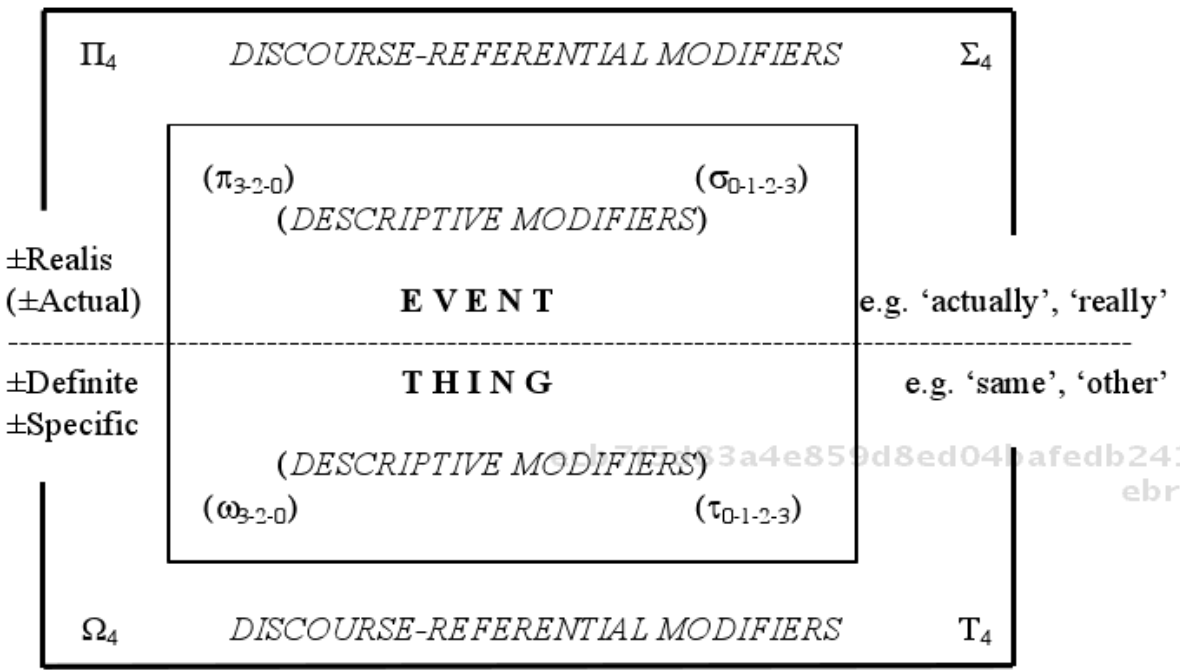

$D R$ operators in the NP

$D R$ satellites in the $N P$

Figure 3. Symmetry in the underlying structure of the clause and the NP:

Discourse-Referential modifiers $\Omega-\Pi-\Sigma-\mathrm{T}$.

\subsubsection{Symmetry between (ir)realis mood and (in)definiteness}

The grammatical categories Realis and Definite are similar in that they both indicate that the entity, i.e. the event or thing referred to by the speaker, (already) has a certain location (is "grounded") in the world of discourse. By contrast, Irrealis and Indefinite signal that the entity referred to by the speaker does not have a proper location (is not "grounded") in the world of discourse - at least not yet. There are thus two symmetries, one linking the grammatical categories Realis and Definite, the other linking Irrealis and Indefinite. 


\begin{tabular}{|c|c|c|}
\hline $\begin{array}{c}\text { Noun Phrase } \\
\text { (thing) }\end{array}$ & $\begin{array}{c}\text { OCCURRENCE IN } \\
\text { WORLD OF DISCOURSE }\end{array}$ & $\begin{array}{c}\text { Clause } \\
\text { (event) }\end{array}$ \\
\hline Definite & $\begin{array}{c}\text { THING OR EVENT (ALREADY) HAS A } \\
\text { LOCATION IN THE DISCOURSE WORLD }\end{array}$ & Realis \\
\hline Indefinite & $\begin{array}{c}\text { THING OR EVENT DOES NOT HAVE A } \\
\text { LOCATION IN THE DISCOURSE WORLD (YET) }\end{array}$ & Irrealis \\
\hline
\end{tabular}

Figure 4. Symmetry between Definite/Realis and Indefinite/Irrealis

\subsubsection{Anti-symmetry between (ir)realis mood and (in)definiteness}

There is also an interesting anti-symmetry between (in)definiteness and (ir)realis (Rijkhoff 1988), which has to do with the number of ways an entity can be definite/indefinite (thing) or actual/non-actual (event). Here Definite aligns with Irrealis in that both definite things (referents of definite noun phrases) and non-actual events (referents of irrealis clauses) can occur in the world of discourse for many different reasons. For example, the referent of an NP can be definite because

- it has been mentioned before (anaphoric use)

(2) I just bought a book and a calendar. Surprisingly, the book was much cheaper than the calendar.

- it is available in the physical context (situational or deictic use)

(3) Now tell me - what do you see on the monitor?

- it is deemed identifiable (or accessible) by the speaker because of socalled "bridging cross-reference" (associative use)

(4) I took a taxi from the station. The driver told me there was a bus strike.

- it is relatively unique in the given contextual setting, so that the hearer can identify it on the basis of his or her general knowledge.

The moon was very bright last night. 
There are also many reasons why reference is made to a non-actual event; for example, because the speaker expresses a wish or a request:

(6) I wish you were here

[interlocutors are not in the same place]

(7) Would you please close the door?

[the door is not closed]

In both cases the speaker refers to an event which has not occurred (yet) and which therefore cannot be located in a particular spatio-temporal region in the world of discourse, i.e. the referent of a non-actual event is not "grounded" in the world of discourse. ${ }^{5}$ All languages have linguistic devices to mark the various kinds of moods (e.g. epistemic, epistemological, deontic) and speech acts (e.g. indicative, imperative, optative) that signal in a more or less indirect fashion to the addressee whether or not reference is being made to an actual event. There are, however, quite a few languages that (also) employ a special realis or irrealis marker for this purpose. One such language is the Papuan language Amele.

Amele (IRR = irrealis; Roberts 1990: 371-372)

Ho $\quad$ bu-busal-eb
pig SIM-run.out-3SG.DS.IRR
'They will kill the pig as it runs out.'

age qo-qag-an

3PL hit-3PL-FUT

'They will kill the pig as it runs out.'

$$
\begin{aligned}
& \text { Ho bu-busal-eb } \\
& \text { pig SIM-run.out-3SG.DS.IRR } \\
& \text { 'Kill the pig as it runs out!' } \\
& \text { Ho } 59 \text { bu-busal-eb }{ }^{-} \text {blb } 2416 \mathrm{c} \\
& \text { pig SIM-run.out-3SG.DS.IRR } \\
& \text { 'Don't kill the pig as it runs out!' }
\end{aligned}
$$$$
\text { (10) } \text { Ho }_{5} \text { bu-busal-eb }
$$

$$
\begin{array}{ll}
\text { age } & \text { qu-ig- } a \\
\text { 3PL } & \text { hit-3PL-IMP }
\end{array}
$$

\section{cain qu-wain}

PROH hit-NEG.F.3PL

By contrast, there is basically one reason why an NP is indefinite: because the entity (thing) designated by the indefinite NP has not been properly introduced into the world of discourse - hence the speaker assumes that the addressee does not know (yet) what particular thing is being referred to.

\section{(11) I took a taxi from the station.}

There is also only one reason why a sentence is in the realis mood: because the entity (event) designated by the sentence is real, i.e. it has happened (or is happening). 
Amele $(\mathrm{R}=$ realis; Roberts 1990: 371-372)

$\begin{array}{llll}\text { (12) Ho bu-busal-en } & \text { age } & \text { qo-igi-a } \\ \text { pig SIM-run.out-3SG.DS.R } & \text { 3PL } & \text { hit-3PL-PRES } \\ \text { 'They are killing the pig as it runs out.' } & \end{array}$

Thus there are many reasons why the speaker may assume the referent of a definite NP to be recoverable for the hearer (anaphoric reference, deictic reference, etc.), but there is basically only way for an event to be actual: because it (has) occurred or is occurring. And vice versa: while there is basically one reason why the speaker assumes the referent of an indefinite NP to be irretrievable (because its referent is unidentifiable / unfamiliar / inaccessible when it is being referred to for the first time), there are numerous reasons why the speaker chooses to refer to a non-actual event. For example, because the speaker expresses a desire, a wish, a hope, a fear, an intention, a possibility, a probability, a request, or a command. ${ }^{6}$

\begin{tabular}{|c|c|c|c|}
\hline $\begin{array}{c}\text { Noun Phrase } \\
\text { (thing) }\end{array}$ & $\begin{array}{c}\text { NUMBER OF WAYS FOR AN } \\
\text { ENTITY TO BE } \\
\text { (IN)DEFINITE OR (IR)REAL }\end{array}$ & $\begin{array}{c}\text { Clause } \\
\text { (event) }\end{array}$ \\
\hline Definite & MANY & ONE & Realis \\
\hline Indefinite & ONE & MANY & Irrealis \\
\hline
\end{tabular}

Figure 5. Anti-symmetry between Definite/Realis and Indefinite/Irrealis.

\subsubsection{The role of specificity in explaining the relationship between} (ir) realis mood and (in) definiteness

In order to explain symmetrical and anti-symmetrical relations between (ir)realis and (in)definiteness we need to distinguish between specific and non-specific indefinite reference. Consider the following examples (Karttunen 1976):

Specific-indefinite reference:

(13) Max wants a dog. It is black.

Nonspecific-indefinite reference:

(14) Max wants a dog. It must be black. 
These examples show that there are two ways to continue "Max wants a dog". The difference is due to the fact that in (13) reference is made to a specific dog ("Max wants a certain dog, which is known to be black"), whereas in (14) the speaker does not refer to any particular dog (English has no special article for specific or non-specific reference unlike, for example, many Polynesian or sub-Saharan African languages).

It will be recalled that realis events and definite things are located in a certain spatio-temporal region in that world of discourse; in other words, these events and things can be said to be grounded in that world of discourse. There is a difference, however, in that realis events, which are typically tensed (if the language uses tense marking), ground themselves upon being referred to by the speaker, whereas definite things often first need to be introduced by an indefinite NP before they can be grounded.

Referents of irrealis clauses (see examples 8-10) and nonspecificindefinite NPs (as in 14) are events and things that may also be said to exist in some fashion once they have been mentioned (since it is possible to refer to them anaphorically), but they are not grounded in the world of discourse: it is impossible to say where or when they are actually occurring or have occurred.

By contrast, referents of specific-indefinite NPs (such as "a whale" in We could see a whale) are grounded immediately in the world of discourse once they have been referred to by the speaker (see also 13 ). ${ }^{7}$ In this sense referents of specific-indefinite NPs are like realis events in that they ground themselves (anti-symmetry). ${ }^{8}$

Notice that non-actuality of an event does not necessarily mean that tense is always absent (in languages that have tense marking). When tense is used for a non-actual event, it specifies when an event was non-actual. The following example from Nyigina (Australia) illustrates:

Nyigina (Stokes 1982: 24)

marlu wa-la-ma-na

NEG 3SG-NF.IRR-go-PAST

'He didn't go to Derby'

\section{burrula-yana}

Derby-ALL

Summing up, we can now say that the symmetry between (in)definiteness and (ir)realis is due to the fact that

(a) definite and realis indicate that the thing or event being referred to by the speaker is grounded (occupies a certain spatio-temporal region) in the world of discourse, and 
(b)nonspecific-indefinite and irrealis indicate that the thing or event being referred to by the speaker is not grounded (does not occupy a certain spatio-temporal region) in the world of discourse.

\begin{tabular}{|c|c|c|}
\hline $\begin{array}{c}\text { Noun Phrase } \\
\text { (thing) }\end{array}$ & $\begin{array}{c}\text { OCCURRENCE IN } \\
\text { WORLD OF DISCOURSE }\end{array}$ & Clause (event) \\
\hline Definite & GROUNDED IN DISCOURSE WORLD & Realis \\
\hline $\begin{array}{c}\text { Nonspecific- } \\
\text { indefinite }\end{array}$ & NOT GROUNDED IN DISCOURSE WORLD & Irrealis \\
\hline
\end{tabular}

Figure 6. Symmetry between Definite/Realis and Nonspecific-indefinite/Irrealis.

Fongbe (a Kwa language mainly spoken in Benin) is an example of a language that employs the same marker for realis and definite reference:

Fongbe (Lefebvre 1998: 94, 99; see also Lefebvre and Brousseau 2002)

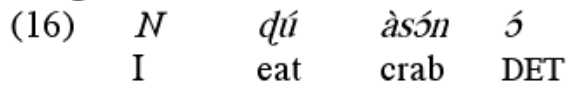

'I ate the crab (in question/that we know of)'

Jan wá ó

John arrive DET

'Actually, John arrived'

Jacaltec (Mayan) uses the same marker for irrealis and nonspecificindefinite reference (the variation is due to vowel harmony):

Jacaltec (Craig 1977: 93, see also Martin 1998)

\begin{tabular}{|c|c|c|c|}
\hline 8) & $\begin{array}{lc}W a y-o j & a b \\
\text { sleep-OJ } & \text { EXH } \\
\text { 'Would that he slept!' }\end{array}$ & $\begin{array}{l}\text { naj } \\
\text { CLF/he } \\
\text { [irrealis 1 }\end{array}$ & ood] \\
\hline 19) & $\begin{array}{l}X-\varnothing \text {-'oc heb } \\
\text { ASP-ABS.3-start PL } \\
\text { hun-uj munlabel } \\
\text { INDEF-OJ pot } \\
\text { 'The women started l } \\
\text { [nonspecific-indefinit }\end{array}$ & $\begin{array}{l}i x \\
\text { woman }\end{array}$ & $\begin{array}{l}s a y-a^{\prime} \\
\text { look_for-FUT }\end{array}$ \\
\hline
\end{tabular}


Summing up, anti-symmetry between (in)definiteness and (ir)realis is due to the fact that

(a) there is basically one way for an entity to be indefinite (thing) or actual (event); also, referents of specific-indefinite NPs and realis clauses "ground themselves" in the world of discourse when being referred to for the first time.

(b) there are numerous ways an entity can be definite (thing) or less than completely actual (event).

\begin{tabular}{|c|c|c|c|}
\hline $\begin{array}{c}\text { Noun Phrase } \\
\text { (thing) }\end{array}$ & \multicolumn{2}{|c|}{$\begin{array}{c}\text { NUMBER OF WAYS FOR AN } \\
\text { ENTITY TO BE } \\
\text { (IN)DEFINITE OR (IR)REAL 9 d 8 e }\end{array}$} & $\begin{array}{c}\text { Clause } \\
\text { (event) }\end{array}$ \\
\hline Definite & MANY & $\begin{array}{c}\text { ONE } \\
\text { (GROUNDS ITSELF) }\end{array}$ & Realis \\
\hline $\begin{array}{c}\text { Specific- } \\
\text { indefinite }\end{array}$ & $\begin{array}{c}\text { ONE } \\
\text { (GROUNDS ITSELF) }\end{array}$ & MANY & Irrealis \\
\hline
\end{tabular}

Figure 7. Anti-symmetry between Definite/Realis and Specific-indefinite/Irrealis.

\subsubsection{On the representation of speaker attitude}

I would like to make clear at the outset that this section is not concerned with attitudinal modifiers as described in Dik (1997: 295f.), which specify the speaker's mental or cognitive attitude towards higher-order entities in the discourse world, such as the propositional contents of his or her own utterance, as in:

(20) Fortunately, I could meet her just before she left.

(21) In my opinion, you should sell your shares.

Here I will mostly be concerned with manifestations of the speaker's emotional attitude such as sympathy or scorn towards animate entities. For example, in many languages the diminutive is used to express affection (Jurafsky 1996): 


\section{Dutch}

(22) Ik heb juist met mijn collega-tje

I have just with my colleague-DIM talked 'I just talked to my colleague.'

gesproken

Adjectives like "poor" can also be used in constructions that express the speaker's sympathy towards another, most typically human or animate entity:

\section{Look at those poor campers - their sleeping bags are soaking wet.}

In a recent article Hengeveld (2004b) has argued that poor in (23) is an instance of a special category of modifiers ("R-modifiers") to be represented at the Interpersonal Level in the FDG model (see also Butler this volume; Keizer 2004: 15). ${ }^{9}$ There are several reasons why I am reluctant to posit a special category of attitudinal modifiers at the Interpersonal Level of the NP model presented above (Figure 3). First of all, a layered model of any linguistic structure is supposed to reflect differences in semantic scope that exist between the various modifier categories. There is, however, no good evidence to show that the scope of poor in the sense of "pitiable" (as in 23) differs from the scope of poor with another sense ("having little money" or "not very skilled"). That is to say, whatever the sense of the attributive modifier poor, it only has the noun in its scope. This does not imply that all adjectives, or rather all qualifying satellites, are equal. Properties denoted by qualifying satellites range from objective/permanent (e.g. "round ${ }_{A}$ table", "wooden ${ }_{A}$ chair") to subjective/temporary (e.g. "ripe A $_{A}$ apple", "new $\mathrm{A}$ book", "good idea" or "splendid $_{\mathrm{A}}$ performance"). This is iconically reflected in the way qualifying adjectives are ordered relative to the head noun: across languages adjectives denoting more inherent (permanent, objective) properties have a strong tendency to occur closer to the head noun than adjectives denoting less inherent (temporary, subjective) properties: ${ }^{10}$

(24) Where did you buy that beautiful round $_{A}$ table? $^{\text {? }}$

(25) ? Where did you buy that round beautiful $_{A}$ table?

Thus, the observation that a modifier such as poor in (23) "embodies the subjective evaluation by the speaker" (Hengeveld 2004b: 373) is no reason to introduce a special category of attitudinal satellites at the Interpersonal 
Level of the NP ("subjective" is not the same as "intersubjective"). ${ }^{11} \mathrm{We}$ noted above that many, perhaps most adjectives reflect some kind of subjective evaluation by the speaker (bad, beautiful, ugly, cute, worthless, interesting). In fact, a wide variety of modifier categories can be said to express subjective evaluations: verbal aspect markers (Comrie 1976: 17), expressions such as half full vs. half empty, adverbial modifiers such as very or rather, forms of address (expressing different degrees of politeness) - they all involve the speaker's subjective evaluation in that another speaker might have said something else under similar circumstances. ${ }^{12}$

Nevertheless it is true that the NP those poor campers in (23) has an additional communicative value in that it displays sympathy for the referent of the phrase on the part of the speaker. However, treating poor as an interpersonal modifier in this construction would imply that the surplus attitudinal value is only situated in the adjective, whereas in fact speaker attitudes such as sympathy or scorn tend to manifest themselves in a variety of ways (morpho-syntactically, prosodically, in voice quality) as a property of a construction rather than through a distinct modifier category represented at one particular layer in the underlying structure (Halliday 2004: 61, 238, 318-9; Butler this volume). In the following example scorn is expressed morpho-syntactically through the use of a distal demonstrative "dat", the diminutive suffix "-je" and postnominal possessive construction "van jou".:"13

\section{Dutch}

(26) Ik vind dat nieuve boek-je van jou helemaal niks I find that new book-DIM of you totally nothing 'I do not think much of that new book (lit. 'booklet') of yours.'

Leaving out the diminutive and using the proximal form of the demonstrative or the prenominal possessive turns the NP into a neutral expression.

\section{Dutch}

(27) Ik vind je nieuwe boek helemaal niks I find your new book absolutely nothing 'I do not think much of your latest book'

Thus it seems that attitudes of the kind discussed here are global properties at the level of a construction rather than a local property that resides in a single modifier. 
How can we capture such global expressions of speaker attitude in FDG? Obviously, when the input from the pre-linguistic conceptual module enters the grammatical component, it must already be clear which part of the structure will be affected by speaker attitude. In FDG one could use, for example, a dotted line to indicate which elements in the underlying representation are within the Attitude Domain, which will effect the form, content and expression of material in that attitude domain. This kind of representation is in fact rather similar to the way discourse pragmatics, in particular Focus Structure, is handled in Role and Reference Grammar (Van Valin and LaPolla 1997: 210-218). In RRG a dotted line is used to mark the potential focus domain (that part of the sentence in which focus can occur) and a triangle indicates what part of the structure is the actual focus domain (the part of the sentence which is in focus).

\subsection{Evidence for the layered NP/clause model}

The fact that in languages such as Jacaltec or Fongbe the same morpheme is used as a discourse-referential operator in the NP and in the clause (section 2.1.3) provides strong support for the NP/clause model defended here. Evidence for the descriptive layers in the NP/clause model in Figure 1 comes from parts-of-speech systems, historical linguistics, cognitive linguistics and morpho-syntax.

As to syntactic evidence, there are 24 ways to linearize a demonstrative, a numeral, an adjective and a noun in a single integral noun phrase, but most logically possible patterns are not attested in the world's languages. Interestingly there are no gaps in the eight "iconic" combinations, i.e. patterns that reflect the layered organization of the NP presented above (with the adjective - typically a qualifying modifier - always next to the noun and the demonstrative - typically a localizing modifier - always in the periphery (Rijkhoff 2004): 
(28)

\section{Iconic patterns} dem num A N

dem num N A

dem A N num

dem N A num

num A N dem

num N A dem

A $N$ num dem

\section{Languages}

Alamblak, Dutch, Georgian, Hungarian, Kayardild, Ket, Nama Hottentot, Imbabura Quechua, Pipil, Tamil, Turkish

Burushaski, Guaraní (also e.g. French and other Romance languages)

Zande

Bambara

Berbice Dutch Creole, Bislama, Sranan

Basque, Hmong Njua

Sango

Oromo, Fa d'Ambu, Nubi

By contrast, languages that employ one of the remaining 16 "non-iconic" patterns as the basic order seem to be extremely rare. Greenberg (1966: 86-87) had one such language in his sample, Kikuyu, which has the order [N dem num A], but Seiler (1978: 322) claims that this is a "less popular variant" in Kikuyu, the normal order being [N A num dem]. Hawkins (1983), whose sample contained over 300 languages, mentioned two other Bantu languages with a non-iconic basic pattern in the NP: Aghem [N A dem num] and Noni (which has $[N$ dem num $A]$ as well as $[N \operatorname{dem} A$ num]). It remains to be seen, however, if the Aghem and Noni sequences are really integral NPs (see Rijkhoff 2002: 272-6 for some arguments to show that we may be dealing with appositional or complex structures rather than simple integral NPs in the case of non-iconic patterns).

There is also evidence from morphology and clause-internal syntax to support the layered model outlined in Figure 1. In English, for example, different kinds of temporal satellites tend to occur in the order time duration ("for a short while" = qualifying satellite), time frequency ("every day or so" = quantifying satellite) and time position ("in January" = localizing satellite), as in Quirk et al. (1985: 551):

\section{I was there for a short while every day or so in January}

Regarding morphological evidence, Bybee's investigation of the ordering of inflectional morphemes relative to the verb in a representative sample of fifty languages revealed that "[...] aspect occurs closest to the stem, followed by tense, and then by mood. The only exception to this ordering found in the 50-language sample is in Ojibwa, where the Dubitative suffix precedes the Preterite suffix" (Bybee 1985: 196). 
Historical evidence to support parallel treatment in the layered analysis of the clause and the noun phrase comes from various sources. For example, Gildea (1993) has shown how demonstratives have developed into tense markers in Panare. Several authors have described phonological similarities between markers of nominal and verbal plurality (see for example Frajzyngier 1977, 1997; Mithun 1988; Newman 1990) and historical connections between markers of collectivity and perfectivity (both: Quality) were already discussed by Von Garnier (1909).

As to lexical word classes, it appears that languages across the globe employ one of the seven major parts-of-speech systems listed in Figure 8 (for a more detailed typology of parts-of-speech systems that also includes intermediate types, see Hengeveld et al. 2004).

\begin{tabular}{|c|c|c|c|c|c|}
\hline \multirow{2}{*}{$\begin{array}{c}\text { Flexible } \\
\text { parts-of-speech } \\
\text { systems }\end{array}$} & Type 1 & \multicolumn{4}{|c|}{ contentive } \\
\cline { 2 - 6 } & Type 2 & \multicolumn{2}{|c|}{ verb } & \multicolumn{2}{|c|}{ non-verb } \\
\cline { 2 - 6 } & Type 3 & verb & \multicolumn{2}{|c|}{ noun } & modifier \\
\hline Rigid & Type 4 & verb & noun & adjective & adverb \\
\cline { 2 - 6 } parts-of-speech & Type 5 & verb & \multicolumn{2}{|c|}{ noun } & adjective \\
\cline { 2 - 6 } systems & Type 6 & \multicolumn{2}{|c|}{ verb } & \multicolumn{2}{|c|}{ noun } \\
\cline { 2 - 5 } & Type 7 & \multicolumn{4}{|c|}{ verb } \\
\hline
\end{tabular}

Figure 8. Parts-of-speech system (adverb = manner adverb; based on Hengeveld 1992: 69).

Apart from quantitative differences (number of distinct word classes, ranging from one to four), languages may also differ with respect to the degree of flexibility displayed by the members of a certain word class. For example, in English the adjective 'beautiful' needs to be provided with an adverbializing suffix $-l y$ before it can modify a verb:

(30) She recorded a beautiful song

(31) She sang beautifully

But there are also languages such as Ngiti (Type 3), which do not distinguish between adjectives and (manner) adverbs (Kutsch Lojenga 1994: 336): 
Ngiti (Kutsch Lojenga 1992: 338)
ngbángba
ní-ìtdì
isó ànò
child
RSM-carry:PRF.PRES light load
'The child carried a light load'
isó ngbángba ní-itdù
ànò
light child RSM-carry:PRF.PRES load
'The child carried the load easily'

In other words, Ngiti and other languages with a Type 3 parts-of-speech system the same element is used as a qualifying modifier ("quality satellite" in Figure 1) in the NP and in the clause.

\subsubsection{A five-layered model of the NP and the clause}

It appears that the four-layered model presented above needs to be expanded with another layer of modification, both for the NP and the clause. This layer concerns classifying modifiers, which further specify the kind of entity denoted by the noun (or verb) and forms the innermost layer of modification, i.e. that between the head constituent and the layer that accommodates qualifying modifiers.

Classifying satellites are lexical items that further specify what kind of entity is being denoted by the head noun, for example: annual in "annual report", presidential in "presidential election", electric in "electric train", or social in "social security". To keep the original numbering of the layers intact, this additional descriptive layer will be referred as the "zero-layer" (Figure 9). ${ }^{14}$

Classifying modifiers typically appear adjacent to the head noun and differ from qualifying modifiers in that they do not specify an objective property of the entity (round table, red car) or the speaker's subjective attitude towards the entity (interesting dissertation, beautiful picture), but rather a particular subclass of the entity in question. Here are some more examples of classifying satellites from English and other languages:

\section{English}
a. a corporate lawyer
b. parental rights
c. a dog's tail
d. a house of $\sin ^{15}$ 
Swedish (Koptjevskaja-Tamm 2003: 539-40)

(35)
a. En folk-et-s
teater
a:C people-DEF.C-GEN
theatre
'a theatre for the people'
b. en skolan-s
a:C school-DEF.C.-GEN task
'a task for the school'

Lithuanian (Koptjevskaja-Tamm 2002: 155)
(36) a. duon-os peilis
bread-GEN knife
'a bread knife'
b. kav-os puodelis
coffee-GEN cup
'a coffee cup'

Clause operators $(\Pi / \pi)$

Clause satellites $(\sigma / \Sigma)$

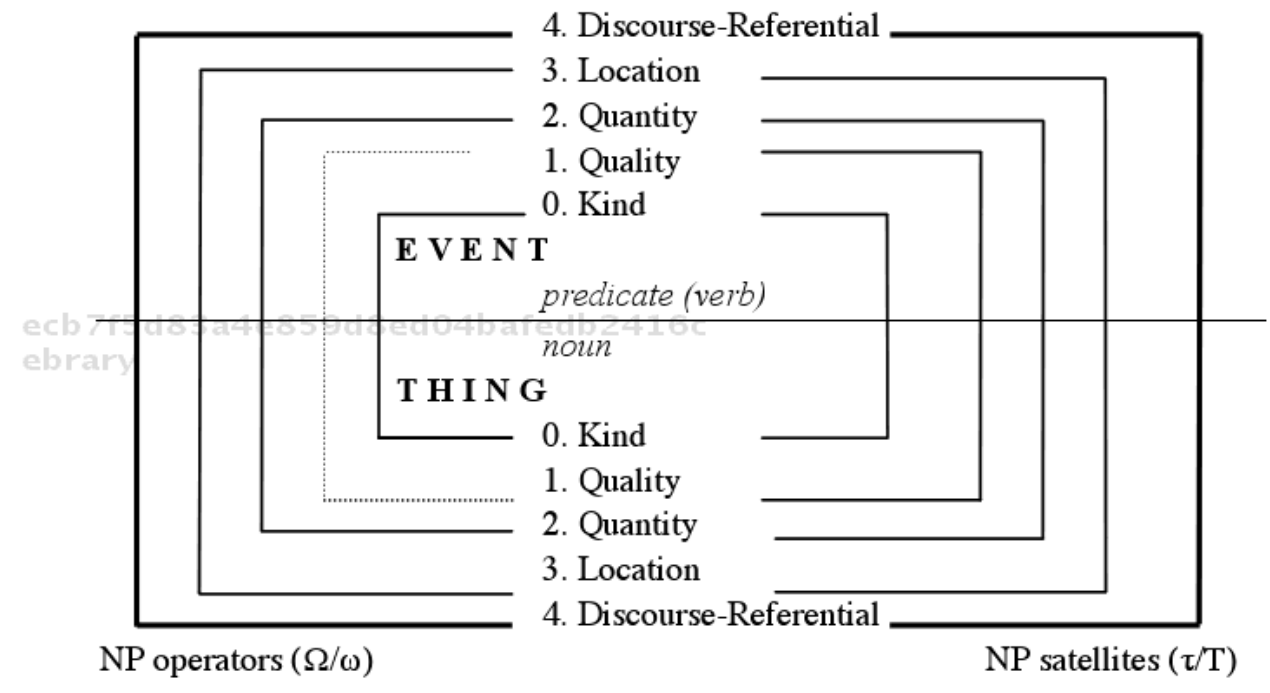

Figure 9. A five-layered NP/clause model: preliminary version (cf. Figure 10).

. Trends in Linguistics, Studies and Monographs : The Noun Phrase in Functional Discourse Grammar. 
Classifying satellites also occur in the kind of classifier construction that is attested in Arrernte and other Australian languages.

Arrernte (Wilkins 2000: 179-200)
a. yerre arlkerrke
b. awelye
arlkerrke
traditional medicine
meat-ant
c. apmere
arlkerrke
socially relevant place
meat-ant

Even though all the constructions in (37) could be translated as "meat ant", Wilkins (2000: 192) states that in each case the semantic effect of the classifying noun is different. For example, the combination awelye arlkerrke in (37b) could be paraphrased as follows:

In using the classifier construction awelye arlkerrke 'traditional medicine meat-ant' in a noun phrase, the speaker wants the addressee to think about the referent of the noun phrase from the point of view of its having the properties of an arlkerrke 'meat-ant' but whose discourse properties at the current point in the discourse are its properties as an awelye 'traditional medicine'.

In other words, the classification is based on the way "meat ant" figures in a particular context: as food in (37a), as a medicine in (37b), or as an entity in a "Dreamtime" narrative in $(37 \mathrm{c})$.

In English classifying adjectives differ from qualifying adjectives in that they usually do not admit intensifiers, comparison, or predicative position (Quirk et al. 1985: 1339; on non-predicative adjectives, see also e.g. Farsi 1968, Levi 1973):

an electric train vs. * a very electric train [intensifier]

(39) a medical examination vs. * a more medical examination [comparison]

(40) the presidential election vs. *the election is presidential [predicative position] 
The semantic range of classifying satellites is rather broad and includes such categories as material, purpose and function, status and rank, origin, and mode of operation (Halliday 2004: 320). Essentially they relate to any feature that may serve to classify entities into a system of smaller sets. The examples show that various forms and constructions may serve as an adnominal classifying satellite (e.g. adjective, noun, genitive NP), and that it may be difficult to draw the line between a noun + classifying satellite combination and compounds or quasi-compounds (cf. also Giegerich 2005). ${ }^{16}$ Furthermore, the same adjective can function either as a classifying or a qualifying satellite (Farsi 1968; Halliday 2004: 319). For example, an adjective such as civil serves as a qualifying satellite in "a civil reply" ("a very civil reply") and as a classifying satellite in "civil rights" (*"very civil rights").

Examples of classifying satellites at the level of the clause are more difficult to find, since it seems they tend to occur as incorporated forms, as in (41b):

Modern Nahuatl (Merlan 1976: 185)

$\begin{array}{cl}\text { (41) a. Kanke eltok } & \text { kočillo } \\ \text { where } 3 . S G: i s & \text { knife } \\ \text { 'Where is the knife?' } & \end{array}$

\section{Incorporation:}
b. $\mathrm{Ya} ?$
ki-kočillo-tete $\boldsymbol{K i}_{\mathrm{i}}$
panci
3.SG 3.SG:it-knife-cut bread
'He cut the bread with a knife'

There is, however, also the phenomenon called "noun stripping" (Miner 1986, 1989; Gerds 1998) or "composition by juxtaposition" (Mithun 1984). Whereas an incorporated element is part of another word, a stripped noun is a separate word (according to phonological criteria such as stress placement), which must appear next to the verb. Thus, in Kusaiean adverbs can appear between verb and object (42a) but not between verb and stripped noun (42b).

Kusaiean (Gerds 1998: 94; original example in K. Lee 1975)

(42) a. Sah el twem upac mitmit sac
Sah he sharpen diligently knife the
'Sah is sharpening the knife diligently'




\section{Stripped noun:}

(42) b. Sah el twetwe mitmit upac

Sah he sharpen knife diligently

'Sah is diligently knife-sharpening'

As in the case of incorporation we see that in (42) a distinction is made between sharpening in general and a certain kind of sharpening, namely knife-sharpening. The crucial difference is that in the case of a stripped noun we are dealing a more or less independent element that serves as a classifying satellite at the level of the clause. ${ }^{17}$

\subsubsection{Classifying operators}

Classifying operators are members of grammatical (rather than lexical) modifier categories which (further) specify what kind of spatial or temporal entity (thing, event) is being referred to. As a matter of fact classifying operators were already represented as a distinct modifier category in the "old" four-layered NP/clause model, where they were erroneously categorized as "qualifying operators" (Figures 1 and 2).

In earlier studies I argued that, just as verbs are coded for a particular Aktionsart ("mode of action"), nouns are lexically coded for a particular Seinsart ("mode of being") such as "mass noun", "set noun", "collective noun", or "singular object noun". Similarly, just as verbal aspects like "perfective" and "imperfective" modify the Aktionsart (Dik 1997: 224f.; note that Aktionsart is also known as lexicalized aspectuality), nominal aspect markers can change the Seinsart of a noun (Rijkhoff 2002: 100121). For example, nouns in Oromo are lexically coded for a Seinsart that I have called "set noun" (i.e. Oromo nouns are transnumeral and can be in direct construction with a numeral), but when they are provided with a (what I call) collective or an individual aspect marker, they designate a special kind of set, viz. a collective set or a singleton set (with just one member) respectively:

Oromo (Stroomer 1987: 76-77, 84-85)

(43) farda 'horse/horses' (unmarked set) vs. fardoollee 'horses' (collective set)

(44) nama 'man/men' (unmarked set) vs. namica 'a/the man' (singleton set) 
It turns out now that the nominal and verbal aspect markers I erroneously regarded as qualifying operators in the "old" four-layered model have to do with "kind" rather than "quality", as was in fact already indicated in the way they were characterized (Rijkhoff 2002: 101): "It is important to make clear at the outset that .. nominal aspect markers .. specify what kind of .. entity is being referred to ..". In other words, aspect markers are classifying rather than qualifying operators in that they relate to the kind of thing (e.g. individual, collective) or event (e.g. process, action) that is being referred to by the speaker. But that leaves us with the question: what about qualifying operators? What is the grammatical equivalent of the qualifying satellite in the NP and in the clause? This is discussed in the next section.

\subsubsection{Do qualifying operators exist?}

Operators are members of modifier categories that are expressed grammatically rather than lexically. They belong to a closed paradigm and manifest themselves morphologically as inflectional modifications of lexical items or as "form" words (also known as grammatical or function words). For example, if the operator value "+Definite" receives morphological expression it typically takes the form of an article or an affix, but note that Definiteness may also be expressed through phonological or syntactic means (Rijkhoff 2002: ch. 6). Since the members of a grammatical word class by definition constitute a smallish, closed set of items, the distinctions expressed by operators are absolute (Dik 1997: 160). For example, if Definiteness is a grammatical category in a language, the only two available choices are + Definite or - Definite (indefinite). More examples are given in Table 1, which shows that operator values in the various semantic domains typically capture a limited number of crucial distinctions (no attempt has been made to give an exhaustive listing of domains or values). 
Table 1. Distinctions in operator categories (based on Dik 1997: 160)

\begin{tabular}{|c|l|}
\hline DOMAIN & \multicolumn{1}{c|}{ VALUE } \\
\hline NUMBER & singular-plural-dual-trial-quadral \\
TENSE & past-present - future \\
POLARITY & positive-negative \\
ASPECT & imperfective-perfective \\
MOOD & deontic-epistemic-epistemological \\
ILLOCUTION & declarative-interrogative-imperative \\
\hline
\end{tabular}

Let us now return to the question posed in the title of this section: "Do qualifying operators exist?" Qualifying modifiers relate to more or less inherent objective or subjective properties of an entity, typically expressed by adjectives - if a language has them. Interestingly all major semantic types of adjective distinguished in Dixon (1982: 16) include gradable properties: dimension ("big" - "bigger" - "biggest"; "fairly big", "extremely big"), physical property ("round", "heavy", "bitter"), colour ("green”), human propensity (“clever", “jealous"), age (“old", “young”), value ("good", "bad"), speed ("fast", "slow"). If gradability is a central feature of qualifying modifiers (as is suggested by these facts), this would explain why there are no qualifying operators: operators do not lend themselves to specifying degrees of some variable property: an object can be

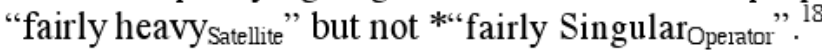

\subsection{Formal representation}

A formal representation of the underlying structure of the NP may appear as in (45). Note that here the interpersonal and the representational levels are conflated, whereas in Hengeveld and Mackenzie's view the two levels co-exist as separate entities (cf. Hengeveld this volume):

$$
\begin{aligned}
& \mathrm{NP}_{\mathrm{i}}: \Omega_{4}\left[\omega _ { 3 } \left[\omega_{2}\left[-\left[\omega_{0}\left[\left(\operatorname{NOUN}\left(\mathrm{f}_{\mathrm{i}}\right)\right)\left(\mathrm{x}_{\mathrm{i}}\right)\right]_{\mathrm{Lc}} \tau_{0}\left(\mathrm{~L}_{\mathrm{c}}\right)\right]_{\mathrm{L} 0} \tau_{1}\left(\mathrm{~L}_{0}\right)\right]_{\mathrm{L} 1}\right.\right. \\
& \left.\left.\tau_{2}\left(\mathrm{~L}_{1}\right)\right]_{\mathrm{L} 2} \tau_{3}\left(\mathrm{~L}_{2}\right)\right]_{\mathrm{L} 3} \mathrm{~T}_{4}\left(\mathrm{~L}_{3}\right)
\end{aligned}
$$

As in (1), each operator $(\omega, \Omega)$ or satellite $(\tau, \mathrm{T})$ takes a certain layer as its argument. For example, quantity layer $L_{2}$ is the argument of operator $\omega_{3}$ and satellite $\tau_{3}$. 
$\Omega / \omega=$ term (NP) operator; the argument of classifying operator $\omega_{0}$ is the innermost layer (the core layer, hence labeled $\mathrm{L}_{\mathrm{C}}$ ), whereas the argument of discourse-referential operator $\Omega_{4}$ is layer $L_{3}$ (which contains all other layers);

$\mathrm{f}=$ predicate variable (here symbolizing the head noun);

$\mathrm{x}=$ referent variable (symbolizes the referent of the NP);

$\tau / T=$ term (NP) satellite; the argument of classifying satellite $\tau_{0}$ is the core layer $\left(\mathrm{L}_{c}\right)$, whereas the argument of discourse-referential satellite $\mathrm{T}_{4}$ is the material contained in localizing layer $\mathrm{L}_{3}$.

\section{Clause OPERATORS}

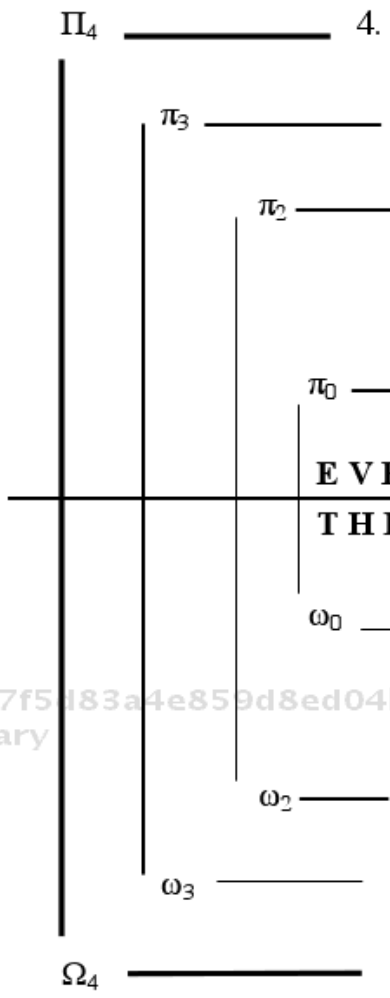

NP OPERATORS
Clause satellites

4. Discourse-Referential

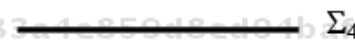
$\sigma_{2}$

3. Location

2. Quantity

1. Quality
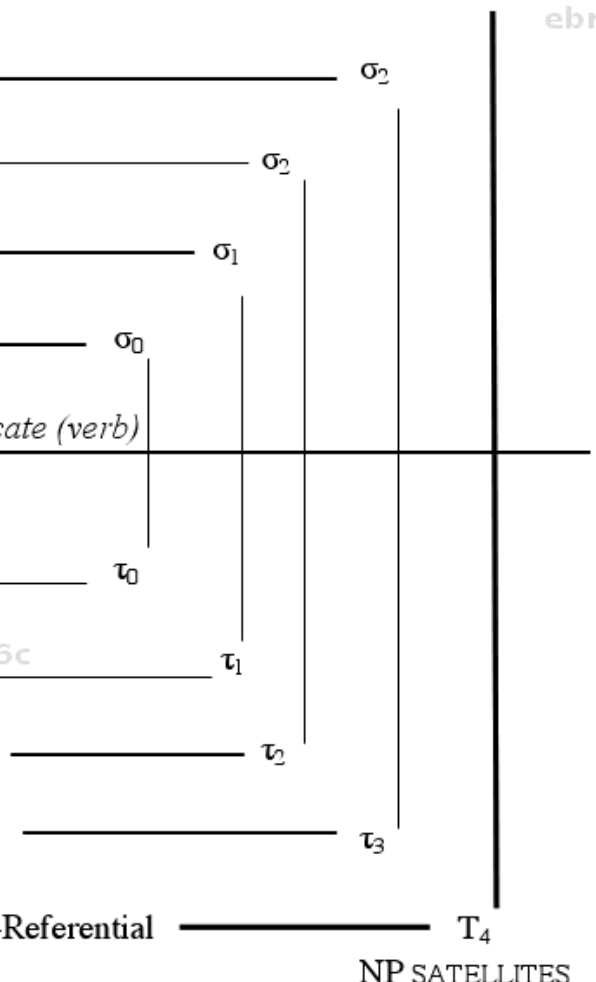

Figure 10. A five-layered NP/clause model. 


\section{Context and FDG}

This section investigates how (elements in) the revised NP structure proposed above interact with contextual factors. ${ }^{19}$ The three main claims of this section are:

(a) the contextual component in the current FDG model must be split up into two separate contextual components (see also Keizer this volume): one for discourse (co-text) and another for the discourse event or "context of situation" (and, by extension, the rest of the external world);

(b) all major components in the FDG model provide a context of some sort: a grammatical context (G-context), a conceptual/cognitive/ mental context (C-context), a discourse context (D-context), and a situational/external context (E-context);

(c) a single rule can account for any kind of contextual influence on a linguistic expression.

\subsection{Components as contexts}

The current FDG model (Figure 11) consists of four interacting modules: one central grammatical unit surrounded by three marginal modules (the conceptual, contextual, and output components).

\subsubsection{The contextual component}

The contextual component is characterized as follows (Hengeveld 2005: 58):

The CONTEXTUAL COMPONENT contains a description of the discourse domain as it has been built up during the current discourse to the extent that this is relevant to the form that subsequent utterances may take. It does not only contain a description of the content and form of the preceding discourse, but also of the actual perceivable setting in which the speech event takes place. 


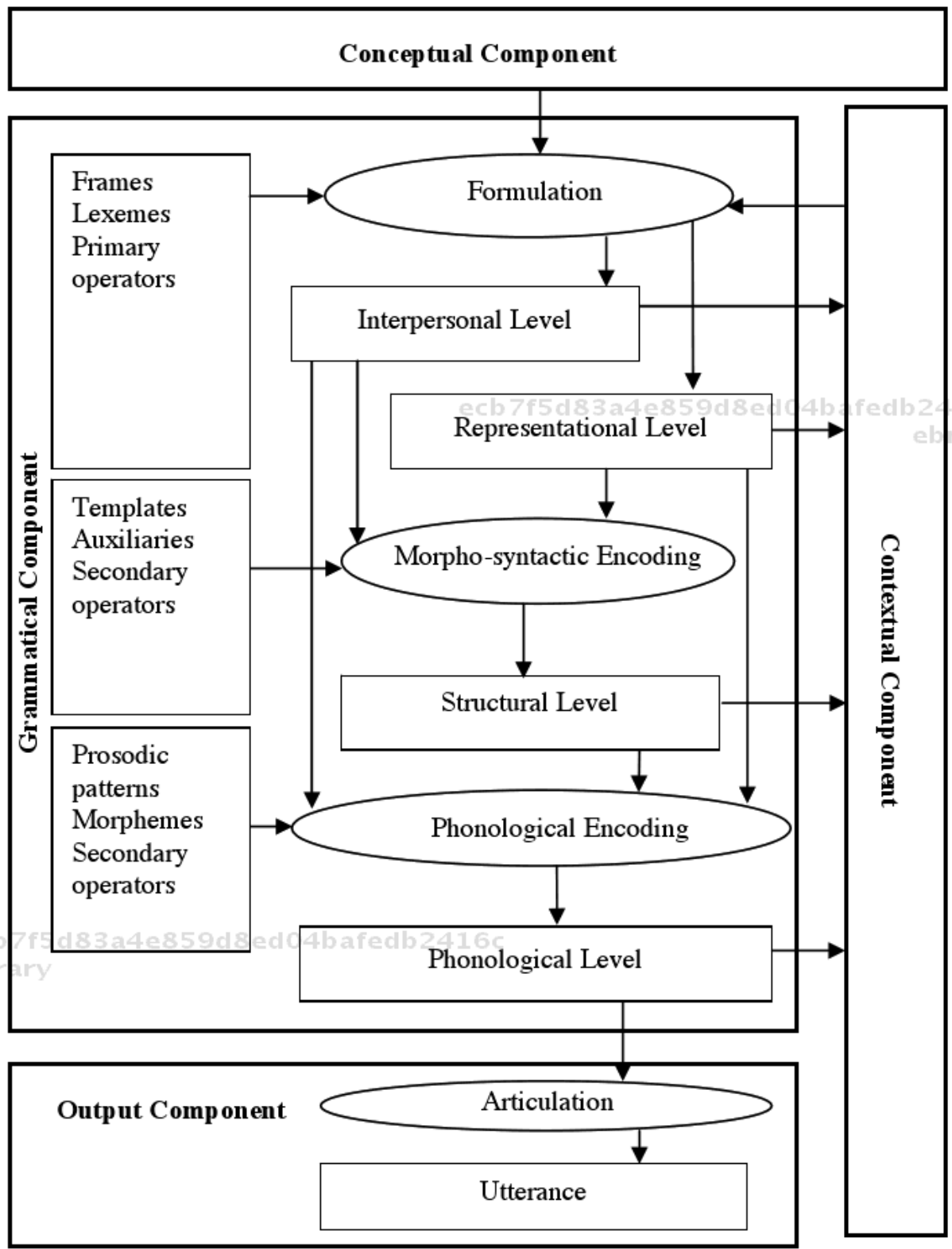

Figure 11. General layout of FDG (Hengeveld 2005: 61).

This description clearly states that the contextual component actually consists of two distinct parts: a textual component (co-text) and a situational 
component. Since FDG is a theory of grammar (rather than a theory of the world), I believe there are several reasons to argue for a strict division between the purely linguistic context and "context of situation" (Malinowski 1923). Firstly, it is important not to confuse different kinds of entities: discourse in the sense of co-text is a linguistic entity, a discourse event is not. $^{20}$ Secondly, discourse as co-text is a finite entity (basically consisting of the linguistic material preceding and following an utterance in some discourse), whereas the external context in which a discourse event takes place is essentially an open-ended phenomenon. ${ }^{21}$ Consequently, we have to be very selective in our representation of the situational context if we want to avoid the impossible (and for linguists: unnecessary) task of having to give a complete description of the physical context, which could mean the entire universe (where does "context of situation" stop? Cf. Searle 1978: $210 \mathrm{f}$.). The discriminative and subjective nature of event representation is also reflected in statements by e.g. Dik (1997: 13) and, more recently, Connolly (2004: 105), who wrote: "Clearly, any contextual description will have to be selective. There is no possibility of including every fact about the situation. The basic principle is to include what one feels to be relevant, insofar as one's knowledge and the evidence permits."

The problem is complicated further by the fact that features of the components of the speech situation (such as sex, age, class, caste, country of origin, generation, region, schooling, ethnicity, kinship relation and degree of intimacy with other speech participants, occupational status; the physical and psychological setting of the speech act; topic and purpose of communication) are often intricately connected, and that their relative importance varies from language to language (Rijkhoff 1998). For example, whereas the social significance of sex is primary in one language, social rank may override all other features in another language (see e.g. ErvinTripp 1972: 224-225 on such differences in the systems of address in Bisaya and Korean).

In my view grammarians must construct and test theories of (discourse) grammar; it is not their task to give a principled account of all the elements in the extralinguistic context that may have an influence on linguistic forms, meanings or functions. Therefore I suggest that one FDG component be strictly reserved for discourse in the sense of co-text (D-context) and another component for those elements in the speech event (E-context) that are considered to have an impact on the form, function, or meaning of (part of) an utterance (see also Butler this volume). 


\subsubsection{The conceptual component}

Hengeveld (2005: 57) gives the following characterization of the conceptual component:

The CONCEPTUAL COMPONENT is not part of the grammar but is the driving force behind the grammatical component as a whole. [...] it represents the conversion of a prelinguistic conceptual representation into the linguistically relevant semantic and pragmatic representations that are allowed by the grammar of the language concerned. The conceptual component is responsible for the development of both a communicative intention relevant for the current speech event and the associated conceptualizations with respect to the relevant events in the external real or imaginary world.

This description more or less covers the notion of context as employed in the cognitive sciences, where context is first and foremost a mental phenomenon. The FDG interpretation of conceptual knowledge also clearly relates to the way context is defined by language philosophers and pragmalinguists: the set of background assumptions that are necessary for an utterance to be intelligible (Ungerer and Schmid 1996: 45-46). I will refer to this component in the FDG model as C-context (see also fn. 19).

\subsubsection{The grammatical component}

The grammatical component constitutes yet another kind of context in the FDG model (G-context). This is the module where the discourse act is analysed pragmatically, semantically, morphosyntactically and phonologically (but see section 4.1). Essentially each level provides another environment containing elements that may affect the form, function or content of (part of) the linguistic expression. For example, at the Representational Level the plural operator is nothing but a contextual element in the underlying representation of the NP that affects the form and meaning of an English nominal predicate in the head slot (Dik 1997: 349).

$$
\mathrm{Pl}\left[\text { book }_{\mathrm{N}}\right]=\text { books }
$$




\subsubsection{The output component}

The actual linguistic expression, which manifests itself as a series of spoken, signed or written symbols, is an entity that is produced and perceived in the external world and which is, therefore, located in space and time. For this reason I regard the output component, which "generates acoustic, signed, or orthographic expressions" (Hengeveld 2004a: 6), as part of the E-context. Obviously, the same goes for the collection of linguistic expressions that together constitute the co-text. However, the internal structures of these two entities (the co-text and its constituent expressions) are $a b$ stract entities to be modelled in the grammatical and the discourse components and as such they are only theoretical constructs that exist in linguists' minds.

\subsection{FDG components: some modifications}

Having motivated the need for a separate component in FDG to account for the influence of elements in the external/situational context (section 3.1.1), and having established that all major components in the FDG model represent some kind of context in the cognitive, anthropological, philosophical, grammatical or textual sense (sections 3.1.2-4), we can now draw the following picture of the components in a revised FDG model.

\begin{tabular}{|c|c|c|}
\hline \multicolumn{3}{|c|}{ E-context (External/Situational Component) } \\
\hline $\begin{array}{l}\text { C-context } \\
\text { (Conceptual } \\
\text { Component) }\end{array}$ & $\begin{array}{l}\text { G-context (Grammatical Component) } \\
\text { a. Interpersonal Level (pragmatic analysis) } \\
\text { b. Representational Level (semantic analysis) } \\
\text { c. Structural Level (morpho-syntactic analysis) } \\
\text { d. Phonological Level (phonological analysis) }\end{array}$ & $\begin{array}{l}\text { D-context } \\
\text { (Discourse } \\
\text { Component) } \\
\text { Co-text }\end{array}$ \\
\hline
\end{tabular}

Figure 12. Contextual components in FDG.

Linguists working in the framework of FDG are mostly concerned with the G-context and the D-context. The most conspicuous difference between the model outlined in Figure 12 and the current FDG model (as represented in 
Figure 11) concerns the organization of the components, but there are also differences regarding the contents of the components. They will be discussed in section 4 .

\subsection{A context rule}

In section $3.1 \mathrm{I}$ argued that the plural operator is an example of a contextual element in the underlying structure of the NP in the grammatical component of the FDG model. The rules that deal with the effect of an operator on some linguistic expression are called "expression rules" in FG (Dik 1997: 349-358) and take the following general format:

\section{Operator [Operandum $]=$ Value}

This rule is easily transformed into a general "context rule" in the FDG model which produces linguistic output for the grammatical component (which in turn can serve as the input for another context rule) $:^{22}$

$$
\text { Context [input] } \rightarrow \text { output }
$$

Thus, the plural formation of English nouns may be accounted for as follows in FDG:

(49) Plural formation in English

G-context: ([.. [.. [PL $\left.\left.\left.\left.\left[-[. .[\mathrm{N}] . .]_{\mathrm{LO}} . .\right]_{\mathrm{L} 1} ..\right]_{\mathrm{L} 2} ..\right]_{\mathrm{L} 3} . ..\right]_{\mathrm{L} 4}\right)$

input: $\quad$ book $_{\mathrm{N}}$

ecb 7 f5 d 8 output: 9 d 8 book $_{\mathrm{N}}$-PL dib $2416 \mathrm{c}$

This could be paraphrased as follows: "if the G-context contains an operator with the value 'PL', the input predicate 'book' is provided with a slot for an inflectional suffix to mark plural number: 'book-PL $L_{\text {Infl }}$ ". The actual form of this inflectional plural suffix is specified at the phonological level and depends on the properties of the input predicate (Dik 1997: 351). This means that, in order to produce the appropriate form, the grammar needs to check the following set of rules: 
(50)

\section{Conditions for plural formation}

1. $\mathrm{Pl}=/ \mathrm{Iz} / \quad$ if last phoneme of input predicate is sibilant; otherwise

2. $\mathrm{Pl}=/ \mathrm{s} / \quad$ if last phoneme of input predicate is voiceless; otherwise,

3. $\mathrm{Pl}=/ \mathrm{z} /$

\section{Plural formation in English}

G-context: N-PL Infl

input: /buk/

[Condition: if the last phoneme of the predicate is voiceless, then $\mathrm{PL}=/ \mathrm{s} /]$

output: /buks/

This could be paraphrased as: "if the G-context (at the phonological level)

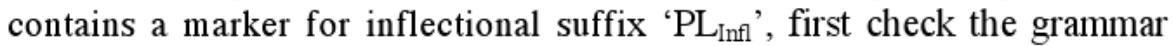
for possible conditions, then substitute ' $\mathrm{PL}_{\text {Infl' }}$ with the appropriate element" (here $/ \mathrm{s} /$ ).

Let us now look at some cases where the form or meaning of a linguistic structure in the grammatical component is sensitive to some contextual element in another component (C-context, D-context, E-context).

\subsubsection{C-context}

The interaction between NP structure in the grammatical component and information in the conceptual component (C-context) is manifested, among other ways, in the value taken by certain operators after the formulator has produced an underlying structure for the grammatical component. For example, the reason why we normally refer to "sun" as a definite entity is due to our long-term knowledge of the world (or rather universe), which is contained in the conceptual component. It is part of our conceptual knowledge that there is only one such entity in our solar system. Since there is no danger that this entity will be confused with another entity of the same type in normal conversation, the speaker may assume that the addressee will be able to identify the intended referent of "the sun" even though this entity may not have been mentioned before or is invisible at the time of speaking. In other words, the fixed value for the discourse-referential operator in the NP "the sun" can only be explained by referring to the Ccontext: 
(52)

\section{Definiteness marking in English}

C-context: the sun is a unique entity in our solar system input: ([value $\Omega_{4}=$ ? [.. [.. [ - [.. [ $\left.\left.\left.\left.\left.\left.\left.\operatorname{sun}_{\mathrm{N}}\right] \ldots\right]_{\mathrm{LO}} ..\right]_{\mathrm{L} 1} ..\right]_{\mathrm{L} 2} ..\right]_{\mathrm{L} 3} ..\right]_{\mathrm{L} 4}\right)$ output: ([value $\Omega_{4}=$ Def. $\left.\left.\left[. .\left[. .\left[-\left[. .\left[\operatorname{sun}_{\mathrm{N}}\right] . .\right]_{\mathrm{LO}} . .\right]_{\mathrm{L} 1} . .\right]_{\mathrm{L} 2} . .\right]_{\mathrm{L} 3} ..\right]_{\mathrm{L} 4}\right)$

\subsubsection{D-context}

The discourse component (D-context) contains a description of the co-text of the utterance. Obviously, FDG needs this component to account for all sorts of reflections of discourse phenomena in a clause, such as tail-head linkage (Hengeveld 2005: 55).

Tidore (Van Staden 2000: 275): tail-head linkage
... turus jafa cahi saloi
ena $=$ ge turus
... then Jafa carry.on.the.back basket
3. $\mathrm{NH}=$ there then

ena $=$ ge paka ine Ine una oka koi 3. $\mathrm{NH}=$ there ascend upwards. upwards 3.SG.M pick banana... '.then Jafa carried the saloi and went upwards. Went upwards he picked the bananas ..'

Discourse phenomena like tail-head linkage, clause-chaining or switchreferencing (cf. de Vries 2005) often require multiple interactions between various components, but a simplified account of tail-head linkage could look like this:

\section{(54) Tail-head linkage in Tidore}

D-context: In episode $\mathrm{E}$ of discourse $\mathrm{D}$, the speaker wants to express coherence between Sentence B (whose underlying structure is being prepared for the grammatical component) and preceding sentence A (which is part of the Dcontext).

Input: prelinguistic version of sentence B in conceptual component.

Output: underlying structure of sentence B in grammatical component ("formulation"), which contains the last word of sentence A.

Condition: at the Structural Level the last word of Sentence A must be the first word in Sentence B. 


\subsubsection{E-context}

Since linguistic expressions are always used by people at a particular time and place, each language has devices to integrate information from the external, situational context. In the FDG model this means that the Econtext needs to be checked for all instances of person, time, and place deixis (notice that here the world of discourse overlaps with the external reality; cf. fn. 19). For example, in Spanish a predicate adjective is marked for the gender of the addressee:

Spanish (Hengeveld 2005: 58)

(55) ¡Qué pálid-a est-ás!

what pale-F.SG COP-IND.PRES.2.SG

'How pale you look!'

(56) Gender marking on adjectival predicate in Spanish:

E-context: Addressee is singular female person

Input: predicative adjective (pálid)

Output: $\quad$ predicative adjective + -a suffix (pálid-a)

In the last couple of decades two more deictic categories have been introduced:

1. discourse deixis, which concerns references to portions of the surrounding discourse;

2. social deixis, which is concerned with the grammaticalization, or encoding in language structure, of social information (Levinson 1987: 93). 23 d 04b a fed b $2416 \mathrm{c}$

Whereas discourse deixis is obviously concerned with the D-context, social deixis must also be explained on the basis of information specified in the E-context. For example, many languages have a set of pronouns for special situations, as when the speaker wants to show respect or deference for the addressee. The impact of the social status of the addressee in the external reality (to be measured relative to the speaker's social status) on the structure in the grammatical component can be captured in the following way: 


\section{Polite form of address in Dutch}

E-context: Addressee is a person who in the current situation needs to be addressed in a respectful fashion by the Speaker.

Input: $\quad \mathrm{A}=2 \mathrm{SG}$

Output: $\quad \mathrm{U}$ [= polite form of $2 \mathrm{SG}$ pronoun]

\section{What is in the grammatical component?}

FDG is a theory of grammar in which the discourse act is the basic unit of analysis. The term "discourse act" is, however, potentially confusing, since it may suggest that the basic unit of analysis is a verbal activity, rather than a linguistic form or construction, i.e. the product of that activity. ${ }^{24}$ This is especially true in studies in which FDG is presented as a dynamic model reflecting the various phases in the process of language production ("from intention to articulation"). I would like to make it clear at the outset of this section that in my view a theory of grammar must provide a model for the analysis of linguistic expressions, not a model of verbal activities or the production process that results in these linguistic expressions (for a similar point see Hengeveld 2004b). In other words, what is being modelled in the grammatical component is not an activity or a process but a linguistic construction (or "pattern"; cf. Fortescue 2004).

So far we have been concerned with the layered structure of the NP and the various modules ("contexts") in the FDG model. This section first takes a closer look at the contents of the grammatical component or G-context. I will argue that the grammatical component is not the place in FDG to describe non-linguistic entities such as (features of) Speaker and Addressee or other aspects of the physical and psychological setting of the speech situation. The G-context must only be used to describe and analyse the form, function and meaning of linguistic constructions.

In section 4.2 I will elaborate on the observed parallels between NPs and clauses (Figure 10, section 2.2.3). It will be argued that descriptive modifiers (concerning Kind, Quality, Quantity, and Location) are specified at the semantic or Representational Level ("language as carrier of content"), whereas discourse-referential and other interpersonal modifiers are specified at the pragmatic level ("language as exchange", "language as communicational process"; Butler 2003: 111; Halliday 2004: 61). The other interpersonal modifiers in the clause inform the Addressee about: 
a. the existential status of a spatial or temporal entity (thing $\mathrm{x}_{\mathrm{i}}$ and event $e_{1}$ ) in the world of discourse (some relevant modifier categories: Definite, Specific, Realis, expressions of objective modality, discourse-referential satellites; section 2.1-3);

b. the modal status of proposition $\mathrm{X}_{\mathrm{i}}$, in particular the speaker's mental or cognitive attitude towards the proposition (some relevant modifier categories: expressions of subjective modality and evidentiality, propositional satellites; Dik 1997: 295-299);

c. the illocutionary status of the clause (some relevant modifier categories: Declarative - Interrogative - Imperative - Exclamative, illocutionary satellites; Dik 1997: 300-307).

This means, among other things, that propositions, which are part of the Representational Level in current FDG, appear at the Interpersonal Level in the version proposed here (section 4.2).

\subsection{The place of speaker and addressee in FDG}

If the grammatical component is concerned with the grammatical analysis of linguistic entities (NP-clause-co-text), this component should not include descriptions of psychological or physical entities that are part of the extra-linguistic context. For example, both Hengeveld (2004b) and Connolly $(2004: 108,112)$ have proposed that the Interpersonal Level can also be used as a platform for the specification of (features of) Speaker $\mathrm{P}_{1}$ and Addressee $\mathrm{P}_{2}$. In current FDG, the linguistic expression (symbolized by $\mathrm{C}=$ communicated content, i.e. the information transmitted in the discourse act) is an argument of an abstract three-place illocutionary predicate (the other two arguments being the Speaker and the Addressee). ${ }^{25}$

$$
\left(\mathrm{M}_{1}:\left[\left(\mathrm{A}_{1}:\left[\mathrm{ILL}\left(\mathrm{P}_{1}\right)_{\mathrm{S}}\left(\mathrm{P}_{2}\right)_{\mathrm{A}}\left(\mathrm{C}_{1}:\left[\ldots\left(\mathrm{T}_{1}\right)\left(\mathrm{R}_{1}\right) \ldots\right]\left(\mathrm{C}_{1}\right)\right)\right]\left(\mathrm{A}_{1}\right)\right)\right]\left(\mathrm{M}_{1}\right)\right)
$$

Figure 13. The Interpersonal Level (Hengeveld 2004a: 5).

In the FDG model defended here, the grammatical component is strictly separated from the external/situational component, which contains (features of) entities that are part of the external, physical world (section 3.1.1). A modified version of the discourse act (i.e. the product) may be 
shown as (58). For the sake of simplicity, the move in (58) consists of one discourse act, which in turn consists of a single, full clause. In (58) the interpersonal and the representational level are connected, but recall that they co-exist as separate entities in Hengeveld and Mackenzie's version (see section 3.2.; the distribution of layers over the Interpersonal and the Representational Level is discussed in section 4.2).

(58) THE UNDERLYING STRUCTURE OF THE CLAUSE

$\left(\mathrm{L}_{\mathrm{c}}=\right.$ core layer; see also (45)):

\section{Interpersonal Level (LANGUAGE AS EXCHANGE)}

Move ${ }_{1}:\left(\left[\Pi_{6}\left[\Pi_{5}\left[\Pi_{4}[\quad \text { E V E N T } 7]_{\mathrm{L}_{3}} \Sigma_{4}\left(\mathrm{~L}_{3}\right)\right]_{\mathrm{L} 4} \Sigma_{5}\left(\mathrm{~L}_{4}\right)\right]_{\mathrm{L} 5} \Sigma_{6}\left(\mathrm{~L}_{5}\right)\right]_{\mathrm{L} 6}\right)$

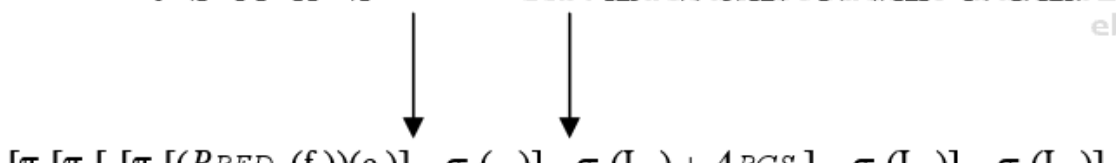

$\left[\pi_{3}\left[\pi_{2}\left[-\left[\pi_{0}\left[\left(P R E D .\left(\mathrm{f}_{\mathrm{i}}\right)\right)\left(\mathrm{e}_{\mathrm{i}}\right)\right]_{\mathrm{Lc}} \sigma_{0}\left(\mathrm{Lc}_{\mathrm{c}}\right)\right]_{\mathrm{LO}} \sigma_{1}\left(\mathrm{~L}_{0}\right)+A R G S .\right]_{\mathrm{L} 1} \sigma_{2}\left(\mathrm{~L}_{1}\right)\right]_{\mathrm{L} 2} \sigma_{3}\left(\mathrm{~L}_{2}\right)\right]_{\mathrm{L} 3}$ Representational Level (LGE. AS CARRIER OF CONTENT; see Fig. 10)

\section{Operators and satellites at the Interpersonal Level: ${ }^{26}$}

$\Pi_{4} / \Sigma_{4}=$ discourse-referential operator / satellite $\left(\mathrm{L}_{3}\right.$ : Event or "State of Affairs" $e_{i}$ )

$\Pi_{5} / \Sigma_{5}=$ proposition operator / satellite $\left(\mathrm{L}_{4}\right.$ : proposition $\left.\mathrm{X}_{\mathrm{i}}\right)$

$\Pi_{6} / \Sigma_{6}=$ illocutionary operator / satellite $\left(L_{5}\right.$ : discourse act $\left.A_{i}\right)$

In (58) the discourse act (a linguistic entity; see note 24) is still the basic unit of analysis within the move (Kroon 1995), but note that the schema does not contain variables for (features of) Speaker or Addressee, and that "Illocution" is an operator category $\left(\Pi_{6}\right)$ rather than an abstract frame (cf. Dik 1997: 66-7, 300f.).

4.2. Parallels between the NP and the clause revisited: the place of modal categories in FDG

In section 2.2.3 I proposed a five-layered model of the NP: four layers to accommodate descriptive modifier categories (classifying, qualifying, quantifying, localizing modifiers) and one layer for modifiers that are concerned with the status of entities in the world of discourse (hence "discourse-referential modifiers"). In the grammatical component of FDG the descriptive modifiers are specified at the Representational (semantic) 
Level, whereas discourse-referential modifiers are specified at the Interpersonal (pragmatic) Level; recall that here we are only concerned with NPs that are used for spatial entities (symbolized by the $\mathrm{x}$-variable):

\section{INTERPERSONAL LEVEL ('LANGUAGE AS EXCHANGE')}

Interpersonal modifiers in the NP are concerned with the status of things in the World of Discourse.

\begin{tabular}{lcc} 
Layer & Operator & Satellite \\
Discourse-Referential & $\Omega_{4}$ & $T_{4}$ \\
\hline REPRESENTATIONAL LEVEL ('LGE. AS CARRIER OF CONTENT')
\end{tabular}

Descriptive modifiers specify properties of an entity in the World of Discourse in terms of Kind, Quality, Quantity, and Location

Layer
Location
Quantity
Quality
Kind

\section{Operator}

$\omega_{3}$

$\omega_{2}$

$\omega_{0}$
Satellite

$\tau_{3}$

$\tau_{2}$

$\tau_{1}$

$\tau_{0}$

Figure 14. NP layers at the Interpersonal and the Representational Level.

If we now also include the other layers in the underlying structure of the clause, we see that two layers must be added: 


\section{INTERPERSONAL LEVEL ('LANGUAGE AS EXCHANGE') \\ At the Interper'sonal Level, modifiers are concerned with the Interpersonal Status of four kinds of entities in the World of Discourse: [i] clauses (or rather the messages contained in the clauses), [ii] propositions, [iii] events and [iv] things.}

\section{MOdIFIERS IN THE CLAUSE}

6. Illocutionary modifiers $\left(\Pi_{6}, \Sigma_{6}\right)$ inform Addressee about the illocutionary status of the clause (Decl, Int, ...).

\section{Proposition modifiers $\left(\Pi_{5}, \Sigma_{5}\right)$} $i$ inform $\mathbf{A}$ about $\mathbf{S}$ 's personal j assessment of / attitude towards a proposition $X_{i}$ as regards the probability, possibility or desirability

\section{MODIFIERS IN THE NOUN PHRASE} of the actual occurrence of event $\mathrm{e}_{\mathrm{i}}$.

\section{Discour'se-Ref. modifier's $\left(\Omega_{4}, \mathrm{~T}_{4}\right)$ i 4. Discourse-Ref. modifier's $\left(\Pi_{4}, \Sigma_{4}\right)$} specify the existential status of thing $\mathrm{x}_{\mathrm{i}}$ or event $\mathrm{e}_{\mathrm{i}}$ in the World of Discourse.

REPRESENTATIONAL LEVEL ('LANGUAGE AS CARRIER OF CONTENT') At the Representational Level, modifiers specify properties of spatio-temporal entities (things, events) in the World of Discourse in terms of the notions Kind (Class), Quality, Quantity, and Location.
3. Localizing modifiers $\left(\omega_{3}, \tau_{3}\right)$
3. Localizing modifiers $\left(\pi_{3}, \sigma_{3}\right)$
2. Quantifying modifier's $\left(\omega_{2}, \tau_{2}\right)$
1. Qualifying modifiers $\left(\tau_{1}\right)$
2. Quantifying modifier's $\left(\pi_{2}, \sigma_{2}\right)$
0. Classifying modifiers
$\left(\omega_{0}, \tau_{0}\right)$
1. Qualifying modifier's $\left(\sigma_{1}\right)$
0 . Classifying modifiers $\left(\pi_{0}, \sigma_{0}\right)$

Figure 15. NP and clause layers at the Interpersonal and the Representational Level (Rijkhoff fc. a).

Figure 15 shows that we find three layers of modification at the Interpersonal Level, each of which is concerned with language as an instrument of social interaction (Dik 1997: 5): $:^{27}$

(i) discourse-referential modifiers, which inform the Addressee about the status of first and second order entities in the world of discourse (e.g. Definite, Realis). These modifiers specify whether or not an entity occupies a certain spatio-temporal region in the discourse world. Or they may 
indicate the chance of occurrence of an event as measured against the background of the speaker's knowledge of the world and systems of moral, legal, or social norms (i.e. expressions of objective modality; Dik 1997: 241-3).

(ii) proposition modifiers, which inform the Addressee about the status of a proposition (a third-order entity) in the discourse. They specify the speaker's mental or cognitive attitude towards (or personal assessment of) proposition $\mathrm{X}_{\mathrm{i}}$ with regard to the probability, possibility or desirability of event $\mathrm{e}_{\mathrm{i}}$ actually taking place. Interestingly, propositions (symbolized by the p-variable in Figure 16 below) appear at the Representational Level in FDG, despite the strong interpersonal nature of propositional modifiers (Halliday 2004: 146-150). ${ }^{28}$

$$
\left(\mathrm{p}_{\mathrm{i}}:\left[\left(\mathrm{e}_{\mathrm{i}}:\left[\left(\mathrm{f}_{\mathrm{i}}\right)\left(\mathrm{x}_{\mathrm{i}}\right)\right]\left(\mathrm{e}_{\mathrm{i}}\right)\right)\right]\left(\mathrm{p}_{\mathrm{i}}\right)\right)
$$

Figure 16. The representational level in FDG (Hengeveld 2004a: 6).

I consider propositional modifiers to be part of the Interpersonal Level, because they clearly contain an instruction on the part of the speaker indicating to what extent statement $\mathrm{X}_{\mathrm{i}}$ about event $\mathrm{e}_{\mathrm{i}}$ can be taken to be true or factual by the addressee. The relevant modifier categories are attitudinal satellites and expressions of evidentiality or subjective modality (Dik 1997: 295-6).

(iii) illocution modifiers, which inform the Addressee about the status of the message (a fourth-order entity). These modifiers specify how the message that is being communicated should be interpreted: as a statement (declarative), a question (interrogative), etc. (Sadock and Zwicky 1985).

\section{Conclusion}

This article argues that the Interpersonal Level in the grammatical component of the FDG model accommodates three layers of modification, each of which is concerned with "language as exchange" or "language as communicational process" (Butler 2003: 111; Halliday 2004: 61): one for clauses (fourth-order entities), one for propositions (third-order entities) and one for things or events (first and second order entities, respectively). All three layers are relevant for the analysis of clauses at the Interpersonal Level, 
whereas only one is relevant for the analysis of linguistic expressions that are used to talk about concrete things, i.e. noun phrases.

According to the model of FDG defended here, the Representational Level in the grammatical component accommodates four layers of modification for both clauses and NPs. These descriptive layers are concerned with "language as carrier of content" or "language as representation" (Butler 2003: 111) and operators and satellites at this level are distributed over classifying, qualifying, quantifying, and localizing layers of modification (but recall that there are no qualifying operators). Since the speaker's emotional attitude towards persons or things is a global property rather than a lexical feature of a particular modifier category, this is accounted for in terms of an "attitude domain", i.e. that part of the clause that the speaker uses to express his or her emotional attitude (this could be marked by a dotted underscore or other typographical means). This will be an indication that a special (non-lexical) meaning has been added, which will then also trigger the appropriate morpho-syntactic and phonological rules this version of the FDG model, the grammatical component does not contain descriptions of elements from the external world (such as Speaker or Addressee), which is represented by a separate component, and all components are treated as different kinds of contexts:

$\begin{array}{lll}\text { Conceptual component } & \Rightarrow & \text { C-context } \\ \text { Discourse component } & \Rightarrow & \text { D-context (co-text) } \\ \text { External/Situational component } & \Rightarrow & \text { E-context } \\ \text { Grammatical component } & \Rightarrow & \text { G-context }\end{array}$

Finally, it was shown that a single "context rule" can account for the influence that any contextual factor in these components may have on the form, meaning or function of (part of) a clause.

\section{Notes}

1. I am grateful to Daniel García Velasco and J. Lachlan Mackenzie for their valuable comments; the usual disclaimers apply.

2. In this article, "modifier" is used in the broad sense, including both lexical and grammatical modifier categories (satellites and operators).

3. Since the NP as well as its referent (x) can be the referred to anaphorically, both need to be indexed in some fashion in order to be able to distinguish between the two, but I am no longer convinced that the structure proposed in 
Rijkhoff (2002) is the best way to do so. Hence an alternative schema is proposed here, where $\mathrm{x}_{\mathrm{i}}$ symbolizes the referent and the indexed label "NP" stands for the construction that is used to refer to that entity.

4. Although genericity is often discussed together with definiteness and specificity, it is perhaps better regarded as a property of propositions rather than NPs. Whereas one can find many languages with articles for definiteness or specificity, I am not aware of any language that employs a special article for generic reference (Behrens 2005: 276, Rijkhoff fc. a: fn. 7).

5. It is safe to say that there is no consensus on the status of referents, i.e. whether they are entities in the external, physical world or mental representations of entities that exist in a discourse world (cf. Keizer this volume; see also fn. 19). For the sake of the argument I will simply assume that in a normal conversation speaker and hearer set up a shared world of discourse in which realis clauses are used to refer to events that are deemed to have a correlate in the external, physical world and in which irrealis clauses are used to refer to events that may or may not have a counterpart in the external world.

6. Chung and Timberlake (1985: 241) wrote: "Whereas there is basically one way for an event to be actual, there are numerous ways that an event can be less than completely actual." Apparently the converse holds for things: whereas there is basically one way for a thing to be indefinite, there are numerous ways for a thing to be definite (Rijkhoff 1988).

7. Cf. Von Heusinger (2002a: 2): "[..] specificity .. is .. to be characterized as the property of an NP being referentially anchored". See Von Heusinger (2002b) for a recent discussion of the notion "specificity".

8. The difference between referents of specific and nonspecific-indefinite NPs may also have to do with the fact that in the case of nonspecific reference we need to set up separate discourse worlds for the various interlocutors (rather than having just one shared world of discourse for both speaker and hearer; $\mathrm{cf}$. Kamp 2004).

9. As to the other meanings of "poor" (1. Impecunious; 2. Badly skilled or trained) one could hypothesize that each sense of "poor" highlights a different set of meaning components of the nominal predicate "doctor" (cf. Huang and Ahrens 2003 on classifier coercion of nouns). Thus, "poor-1" relates to features concerning personal, human qualities (poor as a person), whereas "poor2 " highlights semantic features having to do with professional qualities (poor qua doctor). Essentially the same procedure is used to account for the semantics of flexible parts-of-speech (see Hengeveld et al. 2004, Hengeveld and Rijkhoff 2005, Rijkhoff fc. b).

10. See e.g. Farsi (1968); Clark and Clark (1977: 474); Hetzron (1978); Ney (1982, 1983); Fries (1985); Sichelschmidt (1986).

11. See Traugott and Dasher (2001) and Smith (2004) on diachronic developments from subjective to intersubjective. 
12. In Tongan a speaker's sympathy toward the referent of an NP is expressed by selecting a special "emotional determiner" (Churchward 1953, Hendrick 2005: 908). Tomasello (2003: 12) notes that "linguistic symbols are fundamentally perspectival in the sense that a person may refer to one and the same entity as dog, animal, pet, or pest, or the same event as running, fleeing, moving, or surviving - depending on the communicative goals with respect to the listener's attentional states [...]".

13. The Interpersonal Level in FDG was inspired by the interpersonal metafunction in Halliday's Systemic Functional Grammar (SFG). But whereas in FDG this level is concerned with discourse and attitudinal phenomena, only the latter are part of the interpersonal metafunction in SFG (discourse phenomena fall under the textual component). It may also be useful to point out that in SFG no distinction is made between operators and satellites, grammar and lexicon, semantics and pragmatics, indicating that it can be dangerous to simply copy an element of one theory into another. Note furthermore that Hengeveld's analysis of "poor" in (23) as a modifier at the Interpersonal Level may have been motivated by his idea that NPs should be compared with propositions rather than predications (Hengeveld 1998). For this comparison to work, one would need to find a counterpart of subjective modality in the NP. In current FDG, however, subjective mood is represented at the Representational Level (see also section 4.2).

14. See Chappell and McGregor (1989: 28); Quirk et al. (1987: 1339-40); Halliday (2004: 319-320).

15. Apparently a dog's tail is ambiguous, meaning either "the tail of an unidentified canine" or "a particular kind of tail" (Lachlan Mackenzie, personal communication); see also below on the difficulty of distinguishing between classifying and qualifying modifiers without a proper context. Notice furthermore there is a dependency relation between the value of the discourse operator and the function of a satellite (Quirk et al. 1987: 1276). For example, in a definite NP such as the ship's funnel or the funnel of the ship "ship" serves as a localizing or identifying satellite, whereas in an indefinite NP such as a ship's funnel or the funnel of a ship "ship" is a classifying satellite.

16. In addition to the observed relation between compounding and classification there also a connection between inalienability and classification (as in "a mountain top" vs. "the top of a mountain"; for discussion see e.g. Chappell and McGregor 1989).

17. Consider also examples such as "He farmraised salmon for five years" or "She handwashed the laundry".

18. On gradable adjectives see e.g. Cruse (1986: 202f.); for a recent discussion of gradability, see Wechsler (2005). 
19. Some recent studies on the notion of "context" in linguistics are, for example, Akman and Bazzanella (2003) and Givón (2005).

20. The "world of discourse" that is created during the discourse event is also open-ended and could either be represented in the conceptual component (since this component is responsible for "the development of ... the associated conceptualizations with respect to the relevant events in the external real or imaginary world", see section 3.1.2) or in a separate module in the FDG model.

21. On this problem, see also e.g. Givón (1989: 76): "One must, finally, own up to the existence of an irreducible residue, a recalcitrant escape clause concerning the open-endedness of "context". This residue can never be fully captured, however exhaustive and refined one's taxonomy may be."

22. Ultimately this rule is probably due to Frege (1891): Function/Begriff [Argu-16c ment/Gegenstand] $\rightarrow$ Wahrheitswert.

23. Bystander deixis is usually regarded as a subcategory of social deixis and subsumes a variety of linguistic phenomena such as haplology, avoidance styles and secret languages (Rijkhoff 1998).

24. The fact that discourse acts, as well as the acts that they contain (ascriptive acts and referential acts) are said to be "executed" (Hengeveld 2004a: 5-6) also suggests that what is being analysed in FDG are activities rather than the products of these activities.

25. $\mathrm{M}=$ move, $\mathrm{A}=$ discourse act, $\mathrm{Ill}=$ illocution, $\mathrm{C}=$ communicated content, $\mathrm{T}=$ ascriptive subact, $\mathrm{R}=$ referential subact. Since all linguistic constructions are indexed, they can still be connected to Speakers, Addressee and other entities in the non-grammatical modules ("contexts").

26. In theory one could also include operators and satellites at the level of the Move, as in $\left(\Pi_{7}\left[\Pi_{6}[---]_{L 5} \Sigma_{6}\left(L_{5}\right)\right]_{L 6} \Sigma_{7}\left(L_{6}\right)\right)$, where $\Pi_{7}$ is a move operator and $\Sigma_{7}$ a move satellite.

27. There is of course also the pragmatic status of an entity in terms of newsworthiness (topic, focus), but this is realized as a function rather than a modifier.

28. Before the introduction of FDG, the proposition was still part of the Interpersonal Level (cf. Hengeveld 1990: 1, 6; see also fn. 12). 


\section{References}

Akman, Varol and Carla Bazzanella (eds.)

2003 The complexity of context. Journal of Pragmatics 35-3 (special issue on "Context").

Anstey, Matthew P.

2004 Functional Grammar from its inception. In: J. Lachlan Mackenzie and María Á. Gómez-González (eds.), A New Architecture for Functional Grammar, 22-71. Berlin/New York: Mouton de Gruyter.

Bateson, Gregory

1979 Mind and Nature: a Necessary Unity. New York: Dutton.

Behrens, Leila

2005 Genericity from a cross-linguistic perspective. ${ }^{\text {Linguistics }}$ 43-2: 275-344.

Butler, Christopher S.

2003 Structure and Function: a Guide to Three Major StructuralFunctional Theories. Part 1: Approaches to the Simplex Clause; Part 2: From Clause to Discourse and Beyond. Amsterdam: Benjamins.

this vol. Interpersonal meaning in the noun phrase.

Bybee, Joan L.

1985 Morphology: A Study of the Relation between Meaning and Form. (Typological Studies in Language 9.) Amsterdam: Benjamins.

Chappell, Hillary and William McGregor

1989 Alienability, inalienability and nominal classification. In: Kiria Hall, Michael Meacham and Richard Shapiro (eds.), Proceedings of the Fifteenth Annual Meeting of the Berkeley Linguistics Society, February 18-20, 1989. General Session and Parasession on Theoretical ecb $7 f 5$ d 83 a4 e8 Issues in Language Reconstruction, 24-36. Berkeley: Berkeley Linebrary guistics Society.

Chung, Sandra and Alan Timberlake

1985 Tense, aspect, and mood. In: Timothy Shopen (ed.), Language Typology and Syntactic Description. Volume III: Grammatical Categories and the Lexicon, 202-258. Cambridge: Cambridge University Press.

Churchward, C. Maxwell

1953 Tongan Grammar. London: Oxford University Press. 
Clark, Herbert H. and Eve V. Clark

1977 Psychology and Language: An Introduction to Psycholinguistics. New York: Harcourt Brace Jovanovich.

Comrie, Bernard

1976 Aspect. Cambridge: Cambridge University Press.

Connolly, John H.

2004 The question of discourse representation in Functional Discourse Grammar. In: J. Lachlan Mackenzie and María Á. Gómez González (eds.), A New Architecture for Functional Grammar, 89-116 (Functional Grammar Series 24.) Berlin/New York: Mouton de Gruyter.

Craig, Colette Grinevald

1977 The Structure of Jacaltec. Austin: University of Texas Press.

Cruse, David Alan

1986 Lexical Semantics. Cambridge: Cambridge University Press.

Denning, Keith and Suzanne Kemmer (eds.)

1990 On Language: Selected Writings of Joseph H. Greenberg. Stanford: Stanford University Press.

Dik, Simon C.

1997 The Theory of Functional Grammar. Part I: The Structure of the Clause (Functional Grammar Series 20.) Second, revised edition. Edited by Kees Hengeveld. Berlin/New York: Mouton de Gruyter.

Dixon, Robert M.W.

1982 Where Have All the Adjectives Gone? and Other Essays in Semantics and Syntax. Berlin/New York: Mouton de Gruyter.

Ervin-Tripp, Susan

1972 On sociolinguistic rules: Alternation and co-occurrence. In: John J. Gumperz and Dell Hymes (eds.), Directions in Sociolinguistics: the Ethnography of Communication, 213-250. New York: Holt, Rinehart and Winston.

Escribano, José Luis González

this vol. On noun phrase structure in $\mathrm{F}(\mathrm{D}) \mathrm{G}$ : Some conceptual issues.

Farsi, A.A.

1968 Classification of adjectives. Language Learning 18: 45-60.

Fortescue, Michael

2004 The complementarity of the process and pattern interpretations of Functional Grammar. In: J. Lachlan Mackenzieand María Á. Gómez González (eds.), A New Architecture for Functional Grammar, 151178 (Functional Grammar Series 24.) Berlin/New York: Mouton de Gruyter.

Frajzyngier, Zygmunt

1977 The plural in Chadic. In: Paul Newman and Roxana Ma Newman (eds.), Papers in Chadic Linguistics, 37-56. Leiden: AfrikaStudiecentrum. 
1997 Grammaticalization of number: from demonstratives to nominal and verbal plural. Linguistic Typology 1-2: 193-242.

Frege, Gottlob

1983 Reprint. Function und Begriff (Nachdruck). In: Karel Berka and Lothar Kreiser, Logic-Texte. Kommentierte Auswahl zur Geschichte der modernen Logik, 63-82. (dritte, erweiterte Auflage unter Mitarbeit von S. Gottwald und W. Stelzner). Darmstadt: Wissenschaftliche Buchgesellschaft. First published 1891.

Fries, Peter H.

1985 Towards a discussion of the ordering of adjectives in the English noun phrase. In: Benjamin F. Elson (ed.), Language in Global Perspective: Papers in Honor of the 50th Anniversary of the Summer Institute of Linguistics 1935-1985, 123-133. Dallas: Summer Institute Garnier, K. von of Linguistics.

1909 COM- als perfektierendes Praefix bei Plautus, SAM- im Rigveda, CYN- bei Homer. Indogermanische Forschungen 25: 86-109.

Gerds, Donna B.

1998 Incorporation. In: Andrew Spencer and Arnold M. Zwicky (eds.), The Handbook of Morphology, 84-100. Oxford: Blackwell.

Giegerich, Heinz J.

2005 Associative adjectives in English and the lexicon-syntax interface. Journal of Linguistics 41-3: 571-591.

Gildea, Spike

1993 The development of tense markers from demonstrative pronouns in Panare (Cariban). Studies in Language 17-1: 53-73.

Givón Talmy

1989 Mind, Code and Context: Essays in Pragmatics. Hillsdale NJ: Lawrence Erlbaum.

2005 Context as Other Minds: the Pragmatics of Sociality, Cognition and Communication. Amsterdam: Benjamins.

Greenberg, Joseph H.

1966 Some universals of grammar with particular reference to the order of meaningful elements. In: Joseph $\mathrm{H}$. Greenberg (ed.), Universals of Language ( $2^{\text {nd }}$ edition), 73-113. [Reprinted in Denning and Kemmer (eds.), 40-70.] Cambridge: The MIT Press.

Halliday, Michael Alexander Kirkwood

2004 An Introduction to Functional Grammar (third edition, revised by Christian M.I.M. Matthiessen). London: Arnold. 
Hawkins, John A.

1983 Word Order Universals. (Quantitative Analyses of Linguistic Structure.) New York: Academic Press.

Hendrick, Randall

2005 Tongan determiners and semantic composition. Language 81-4: 907926.

Hengeveld, Kees

1990 The hierarchical structure of utterances. In: Jan Nuyts, A. Machtelt Bolkestein and Co Vet (eds.), Layers and Levels of Representation in Language Theory: a Functional View, 1-23. Amsterdam: Benjamins.

1992 Non-Verbal Predication: Theory, Typology, Diachrony. Berlin/New York: Mouton de Gruyter.

1998 Terms and propositions. Paper read at the Eight International Conference on Functional Grammar (ICFG8), Free University Amsterdam, 8 July 1998.

2004a The architecture of a Functional Discourse Grammar. In: J. Lachlan Mackenzie and María Á. Gómez González (eds.), A New Architecture for Functional Grammar, 1-21. (Functional Grammar Series 24.) Berlin/New York: Mouton de Guyter.

2004b Epilogue. In: J. Lachlan Mackenzie and María Á. Gómez González (eds.), A New Architecture for Functional Grammar, 365-378. (Functional Grammar Series 24.) Berlin/New York: Mouton de Guyter.

2005 Dynamic expression in Functional Discourse Grammar. In: Casper de Groot and Kees Hengeveld (eds.), Morphosyntactic Expression in Functional Grammar, 53-86. Berlin/New York: Mouton de Gruyter.

this vol. Prototypical and non-prototypical noun phrases in FDG.

Hengeveld, Kees and J. Lachlan Mackenzie

2005 Interpersonal functions, representational categories, and syntactic templates in Functional Discourse Grammar. In: María Á. GómezGonzález and J. Lachlan Mackenzie (eds.), Studies in Functional Discourse Grammar, 9-27. Bern: Peter Lang.

2006 Functional Discourse Grammar. In: Keith Brown (ed.), Encyclopedia of Language and Linguistics, 2nd Edition, Vol. 4, 668-676. Oxford: Elsevier.

Hengeveld, Kees and Jan Rijkhoff

2005 Mundari as a flexible language. Linguistic Typology 9-3: 406-431.

Hengeveld Kees, Jan Rijkhoff and Anna Siewierska

2004 Parts-of-speech systems and word order. Journal of Linguistics 40-3: 527-570.

Hetzron, Robert

1978 On the relative order of adjectives. In: Hansjakob Seiler (ed.), Language universals: Papers from the Conference at Gummers- 
bach/Cologne, Germany October 3-8, 1976, 165-184. Tübingen: Narr.

Heusinger, Klaus von

2002a Specificity and definiteness in sentence and discourse structure. Journal of Semantics 19: 209-211.

2002b The cross-linguistic implementations of specificity. In: K. Jaszczolt and Ken Turner (eds.), Meanings through Language Contrast. Volume 2, 405-421. (Pragmatics and Beyond NS 100.) Amsterdam: Benjamins.

Huang, Chu-Ren and Kathleen Ahrens

2003 Individuals, kinds and events: Classifier coercion of nouns. Language Sciences 25: 353-373.

Jurafsky, Daniel

1996 Universal tendencies in the semantics of the diminutive. Language 72-3: 533-578.

Kamp, Hans

2004 Specific-indefinites and anchored logical form. Paper presented at Copenhagen Determination Symposium, Copenhagen Business School (Denmark), 26 August 2004.

Karttunen, Lauri

1976 Discourse referents. In: James D. McCawley (ed.), Notes from the Linguistic Underground, 363-387. (Syntax and Semantics 7.) New York: Academic Press.

Keizer, Evelien

2004 Term structure in FG: A modest proposal. Working Papers in Functional Grammar 78.

this vol. Reference and ascription in FDG: An inventory of problems and some possible solutions.

Koptjevskaja-Tamm, Maria

2002 Adnominal possession in the European languages: form and function. Sprachtypologie und Universalienforschung (STUF) 55-2: 141-172.

2003 A woman of sin, a man of duty, and a hell of a mess: non-determiner genitives in Swedish. In: Frans Plank (ed.), Noun Phrase Structure in the Languages of Europe, 515-558. Berlin/New York: Mouton de Gruyter.

Kroon, Caroline

1995 Discourse Particles in Latin: a Study of nam, enim, autem, vero and at. Amsterdam: Gieben.

Kutsch Lojenga, Constance

1994 Ngiti: a Central-Sudanic Language of Zaire. Köln: Köppe. 
Lee, $\mathrm{K}$.

1975 Kuseian Reference Grammar. Honolulu: University Press of Hawaii. Lefebvre, Claire

1998 Multifunctionality and variation among grammars: The case of the determiner in Haitian and in Fongbe. Journal of Pidgin and Creole Languages 13-1: 93-150.

Lefebvre, Claire and Anne-Marie Brousseau

2002 A Grammar of Fongbe. (Mouton Grammar Library 25.) Berlin/New York: Mouton de Gruyter.

Levi, Judith N.

1973 Where do all those other adjectives come from? Papers from the ninth regional meeting of the Chicago Linguistic Society, April 1315. In: Claudia Corum, T. Cedric Smith-Stark and Ann Weiser (eds.), You Take the High Node and I'll Take the Low Node. Paper's from the 9th Regional Meeting of the Chicago Linguistic Society, April 13-15, 1973, 332-345. Chicago: Chicago Linguistic Society.

Levinson, Stephen C.

1987 Pragmatics. Cambridge: Cambridge University Press. First published 1983.

Malinowski, Bronislaw

1923 The problem of meaning in primitive language. In: C. Ogden and I. Richards (eds.), The Meaning of Meaning: a Study of the Influence of Language upon Thought and of the Science of Symbolism, 296336. New York: Harcourt, Brace and World.

Martin Laura

1998 Irrealis constructions in Mocho (Mayan). Anthropological Linguistics 40-2: 198-213.

Merlan, Francisca

1976 Noun incorporation and discourse reference in Modern Nahuatl. International Journal of American Linguistics 42-3: 177-191.

Miner, Kenneth L.

1986 Noun stripping and loose incorporation in Zuni. International Journal of American Linguistics 52-3: 242-254.

1989 A note on noun stripping. International Journal of American Lin-

Mithun, Marianne guistics 55: 476-7.

1984 The evolution of noun incorporation. Language 60-4: 847-894.

1988 Lexical categories and the evolution of number marking. In: Michael Hammond and Michael Noonan (eds.), Theoretical Morphology: Approaches in Modern Linguistics, 211-234. New York: Academic Press. 
Newman Paul

1990 Nominal and Verbal Plurality in Chadic. (Publications in African Languages and Linguistics 12.) Dordrecht: Foris.

Ney, J.W.

1982 The order of adjectives and adverbs in English. Forum Linguisticum 6: 217-257.

1983 Optionality and choice in the selection of order of adjectives in English. General Linguistics 23: 94-128.

Quirk, Randolph, Sidney Greenbaum, Geoffrey Leech and Jan Svartvik

1985 A Comprehensive Grammar of the English Language. London: Longman.

Roberts, John R.

1990 Modality in Amele and other Papuan languages. Journal of Linguis-16c tics 26: 363-401.

Rijkhoff, Jan

1988 A typology of operators. Working Papers in Functional Grammar 29.

1998 Bystander deixis. In: Yaron Matras (ed.), The Romani Element in Non-Standard Speech, 51-67. (Sondersprachenforschung 3.) Wiesbaden: Harrassowitz.

2002 The Noun Phrase. (Oxford Studies in Typology and Theoretical Linguistics.) Oxford: Oxford University Press.

2004 Iconic and non-iconic word order patterns: on symmetry in the NP and counter examples to Universal 20. In: Henk Aertsen, Mike Hannay and Rod Lyall (eds.), Words in Their Places: A Festschrift for J. Lachlan Mackenzie, 169-180. Amsterdam: Free University, Faculty of Arts.

fc. a Descriptive and discourse-referential modifiers in a layered model of the noun phrase. Linguistics 46-4 (2008).

fc. b On flexible and rigid nouns (and verbs). To appear in Studies in Language.

Rijkhoff, Jan and Johanna Seibt

2005 Mood, definiteness and specificity: A linguistic and a philosophical account of their similarities and differences. Sprog - Tidsskrift for Sprogforskning 3-2: 85-132.

[http://ojs.statsbiblioteket.dk/index.php/tfs/index]

Sadock, Jerrold M. and Arnold M. Zwicky

1985 Speech act distinctions in syntax. In: Timothy Shopen (ed.), Language Typology and Syntactic Description. Volume I: Clause Structure, 155-196. Cambridge: Cambridge University Press.

Searle, John

1978 Literal meaning. Erkenntnis 13: 207-224. 


\section{Jan Rijkhoff}

Sichelschmidt, Lorenz

1986 Optionality and choice in the analysis of adjective order: comments on Ney. Studia Linguistica 40-2: 135-148.

Seiler, Hansjakob

1978 Determination: A functional dimension for interlanguage comparison. In: Hansjakob Seiler (ed.), Language Universals: Papers from the Conference at Gummersbach/Cologne, Germany October 3-8,

Smith, John Charles 1976, 301-328. Tübingen: Narr.

2004 An analysis of Romance 'ethic' datives. Paper read at the $28^{\text {th }}$ Penn Linguistics Colloquium, 27-29 February 2004, Department of Linguistics, University of Pennsylvania PA, USA.

Staden, Miriam van

2000 Tidore: A linguistic description of a language of the North Moluccas. Ph.D. dissertation, University of Leiden.

Stokes, Bronwyn

1982 A description of Nyigina, a language of the West Kimberley, Western Australia. Ph.D. dissertation, Australian National University.

Stroomer Harry

1987 A Comparative Study of Three Southern Oromo Dialects in Kenya: Phonology, Morphology and Vocabulary. (Cushitic Language Studies 6.) Hamburg: Buske.

Tomasello, Michael

2003 Constructing a Language: A Usage-Based Theory of Language Acquisition. Cambridge, M.A.: Harvard University Press.

Traugott, Elizabeth Closs and Richard B. Dasher

2001 Regularity in Semantic Change. (Cambridge Studies in Linguistics 97.) Cambridge: Cambridge University Press.

Ungerer, Friedrich and Hans-Jörg Schmid

1997 An Introduction to Cognitive Linguistics. London/New York: Longman.

Vries, Lourens de

2005 Towards a typology of tail-head linkage in Papuan languages. Studies in Language 29-2: 363-384.

Van Valin, Robert D., Jr. and Randy J. LaPolla

1997 Syntax. Structure, Meaning and Function. Cambridge: Cambridge University Press.

Wechsler, Stephen

2005 Weighing in on scales: A reply to Goldberg and Jackendoff. Language 81-2: 465-473. 
Wilkins, David P.

2000 Ants, ancestors and medicine: A semantic and pragmatic account of classifier constructions in Arrernte (Central Australia). In: Gunter Senft (ed.), Systems of Nominal Classification, 147-216. (Language, Culture and Cognition 4.) Cambridge: Cambridge University Press. 
. Trends in Linguistics, Studies and Monographs : The Noun Phrase in Functional Discourse Grammar. : Mouton de Gruyter, . p 124

http://site.ebrary.com/id/10256603?ppg=124

Copyright (@) Mouton de Gruyter. . All rights reserved.

May not be reproduced in any form without permission from the publisher, except fair uses permitted under U.S. or applicable copyright law. 